Research paper

\title{
Deciphering long-term coastal dynamics using IR-RF and ESR dating: a case study from Médoc, south-west France
}

\author{
Sebastian Kreutzer ${ }^{\mathrm{a}, *}$, Mathieu Duval ${ }^{\mathrm{b}}$ c , Melanie Bartz ${ }^{\mathrm{d}}$, Pascal Bertran ${ }^{\mathrm{e}}$, Mathieu Bosq ${ }^{\mathrm{f}}$, Frédérique Eynaudg, \\ Florence Verdin ${ }^{\mathrm{h}}$, Norbert Mercier ${ }^{\mathrm{a}}$ \\ ${ }^{a}$ IRAMAT-CRP2A, UMR 5060, CNRS - Université Bordeaux Montaigne, Pessac, Cedex, France \\ ${ }^{\mathrm{b}}$ Australian Research Centre for Human Evolution (ARCHE), Environmental Futures Research Institute (EFRI), Nathan, QLD, 4111, Australia \\ ${ }^{\mathrm{c}}$ Geochronology, Centro Nacional de Investigación sobre la Evolución Humana (CENIEH), Burgos, Spain \\ d Institute of Geography, University of Cologne, Cologne, Germany \\ e Inrap, Bègles, France \\ ${ }^{\mathrm{f}}$ PACEA, UMR 5199, CNRS - Université de Bordeaux, Pessac, Cedex, France \\ ${ }^{g}$ EPOC - OASU, UMR 5805, CNRS - Université de Bordeaux, Pessac, Cedex, France \\ ${ }^{\mathrm{h}}$ AUSONIUS, UMR 5607, CNRS - Université Bordeaux Montaigne, Pessac, Cedex, France
}

\section{A R T I C L E I N F O}

\section{Keywords:}

IR-RF

ESR

OSL

Médoc

Middle Pleistocene

\begin{abstract}
A B S T R A C T
A proper understanding of local palaeoenvironmental histories is an iterative process. Previously settled interpretations suddenly demand a reconsideration triggered by findings from sites not accessible before. The coastline of the Médoc area in south-west France faced considerable recent erosion, providing new valuable insights into the history of the local Holocene and Pleistocene deposits; mainly of estuarine, lacustrine and aeolian origin. In the framework of the project LITAQ for reconstructing the coastal history of the Aquitaine basin, new recently outcropped sediment profiles have been investigated. To establish the chronological framework, for the first time optically stimulated luminescence (OSL) on quartz, infrared radiofluorescence (IR-RF) on K-feldspar were applied in conjunction with multiple-centres electron spin resonance (ESR) dating on quartz. Our approach combines routine luminescence dating application with methodological investigations, with a focus on IR-RF and ESR dating. IR-RF and ESR ages are consistently older than the OSL ages, presumably due to insufficient bleaching, however, they are consistent within $2 \sigma$. Our study confirms that the investigated area is covered by Holocene sands, following Pleistocene colluvial and aeolian sandy deposits mainly deposited in a periglacial context during MIS 8 and MIS 10. The base of the profiles appears to consist of interglacial estuarine deposits, probably from the Holsteinian (MIS 11), supporting the theory of a progressive replacement of a tide-influenced marsh by a peaty fresh-water pond during that period. Finally, IR-RF and multiple-centres ESR dating can be considered as valuable tools to decipher Middle Pleistocene landscape dynamics.
\end{abstract}

\section{Introduction}

Advances in Quaternary geochronology heavily rely on methodological progressions achieved concerning the chronological toolset. Luminescence dating is one of these tools, and it may be seen as only one method out of many others relevant for Quaternary Sciences. However, its event-based character (e.g., sunlight exposure) enables a direct tracking of geomorphological processes using natural mineral grains (e.g., quartz or feldspar) providing unique insights into the recent Earth's history. Thus, extending the temporal range of luminescence dating methods to decipher sediment transportation processes, e.g., beyond the Late Pleistocene, is a desirable and enduring challenge (e.g., Wintle, 2008). Against this background, our study aims to apply and test a method already proposed two decades ago (Trautmann et al., 1998, 1999): Infrared-radiofluorescence (IR-RF) on K-feldspar. For the first time, we apply IR-RF on potassium-bearing feldspar in conjunction with conventional single aliquot regenerative (SAR) dose optically stimulated luminescence

(OSL,

\footnotetext{
* Corresponding author.

Email address: sebastian.kreutzer@u-bordeaux-montaigne.fr (S. Kreutzer)
} 
Huntley et al., 1985) and electron spin resonance (ESR) dating on quartz using the multiple-centres approach (Toyoda et al., 2000).

In the past, IR-RF has been proposed to significantly enhance the temporal range of luminescence dating techniques up to at least ca. 600 ka (e.g., Wagner et al., 2010; depending on the environmental setting). However, due to a lack of commercially available measurement equipment and doubts raised on its overall reliability (e.g., Buylaert et al., 2012), IR-RF dating applications are still scarce (e.g., Wagner et al., 2010; Novothny et al., 2010; Lauer et al., 2011; Kreutzer et al., 2014; Schaarschmidt et al., 2018). In 2012, the IRAMAT-CRP2A started to reinvestigate IR-RF (Frouin et al., 2015, 2017; Huot et al., 2015; Kreutzer et al., 2017a) and proposed a modified measurement protocol $\left(\mathrm{RF}_{70}\right.$; Frouin et al., 2017) based on the easy to apply IRSAR approach by Erfurt and Krbetschek (2003). In contrast to infrared stimulated luminescence (IRSL, Hütt et al., 1988) on feldspar or its derivates employing higher measurement temperatures (post-IR IRSL, Thomsen et al., 2008; MET, Li and Li, 2011), IR-RF is stimulated by ionising radiation. The measured signal is believed to be a direct measure of the charge trapping process (Trautmann et al., 2000), i.e., without involving recombination centres. In comparison to other luminescence dating techniques (e.g., OSL, IRSL, post-IR IRSL), IR-RF records a full, high-resolution dose-response curve during one stimulation run, dramatically reducing the needed measurement time, in particular for old samples with high palaeodoses ( $>500$ Gy). Furthermore, so far, no study has presented evidence for anomalous fading of the IR-RF signal, an unwanted signal loss over time, which has been reported for IRSL on feldspar (e.g., Wintle, 1973; Spooner, 1992).

In the literature, some studies compared IR-RF to OSL or post-IR IRSL dating results (e.g., Frouin et al., 2017; Schaarschmidt et al., 2018). Such comparison is convenient and likely provides a reliable cross-check if the investigated luminescence signal is not in saturation or suffers from anomalous fading, but it may yield inconclusive results for post-IR IRSL, in particular, if the results for different readout temperatures (MET protocol) are compared. For instance, if mul- tiple, but differing, age results are obtained using post-IR IRSL/MET, it may remain unclear (bleachability vs fading) which of the ages best compare to the one obtained by IR-RF. ESR dating of quartz provides an alternative approach for older sediments, but the often-preferred $\mathrm{Al}$ centre shows a relatively slow bleaching rate leading to an incomplete reset of the signal during sediment transport (e.g., Toyoda et al., 2000; Duval et al., 2017). To minimise this uncertainty, Toyoda et al. (2000) suggested to include further easy-to-bleach centres (namely $\mathrm{TiH}$ and TiLi) in the data analysis. More recently, Duval et al. (2017) even proposed that this 'multiple-centres' approach should become a minimum requirement for analytical procedures in ESR dating of quartz.

At the here presented study site, Médoc (south-west France, cf. Sec. 2 ), the coastline faced considerable recent erosion, providing new valuable insights in the history of the local Holocene and Pleistocene deposits which are of estuarine, lacustrine and aeolian origin. Though the stratigraphy in this area is under investigation since a century (cf. Bosq et al., in press; Faye et al., in press; Stéphan et al., in press), so far, the chronological framework was based only on ${ }^{14} \mathrm{C}$ dating (Fig. 2) and few IRSL ages (Clarke et al., 1999) from Late Holocene dunes (e.g., Dune de la Gastouse, Dune de Labian) in the Médoc area. The work by O'Brien and Jones (2003) on pollen data, challenged the chronological interpretation and tentatively placed the lowermost part of the stratigraphy into the Middle Pleistocene, instead of the Late Pleistocene (Tastet, 1999).

Here, our comparison dating study using OSL, IR-RF and multiple-centres ESR methods aims at providing a better understanding of the dynamic landscape evolution of the Médoc area, and it contributes thus to a revised chronological framework of this area. Our study will reveal erosional discordances and accumulation phases ranging from Marine Isotope Stage (MIS) 8 to MIS 11 (referenced to the data stack by Lisiecki and Raymo, 2005). The results indicate the general accuracy of IR-RF dating and show its potential to decipher Middle Pleistocene Quaternary geochronological histories.

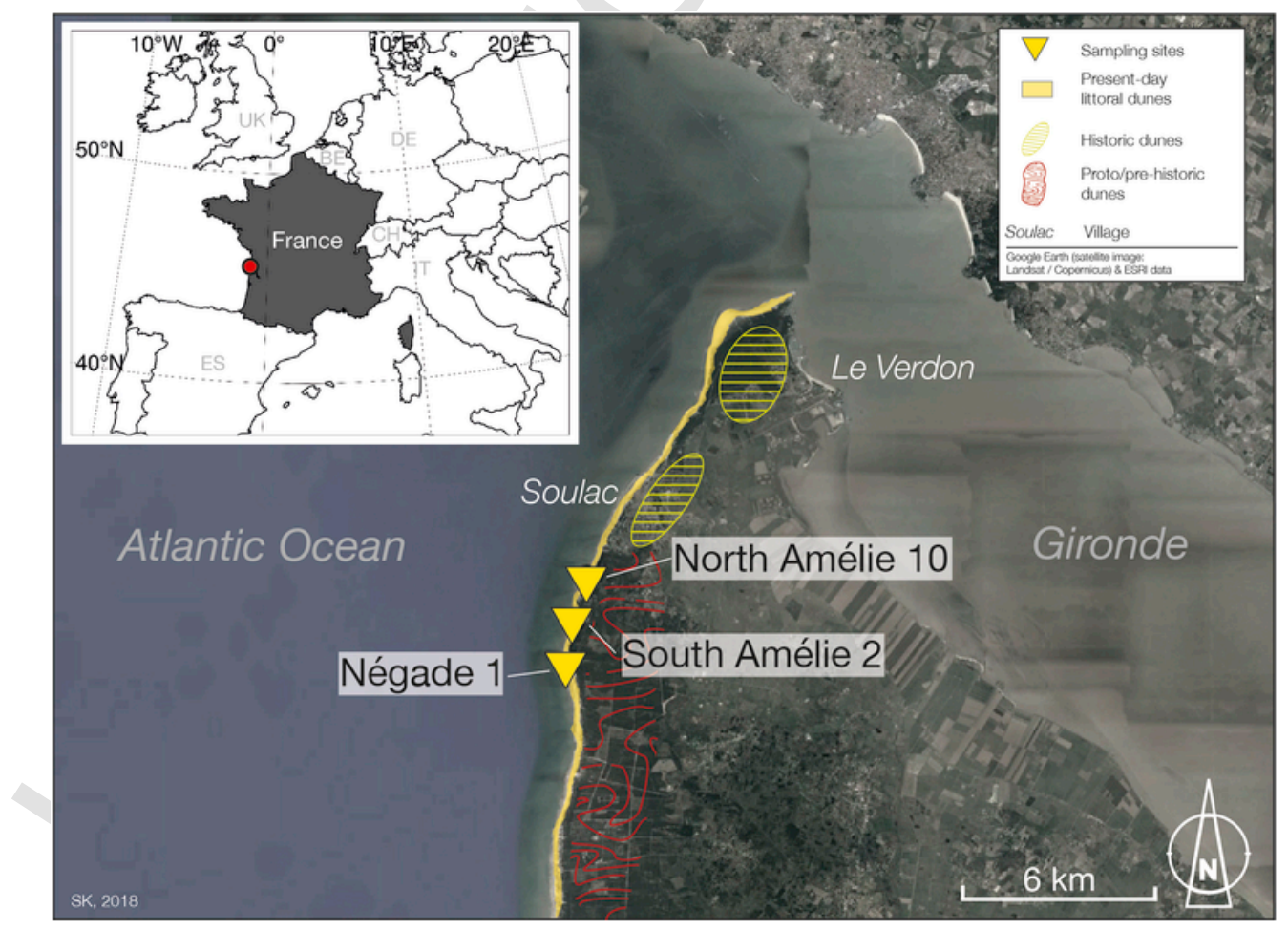

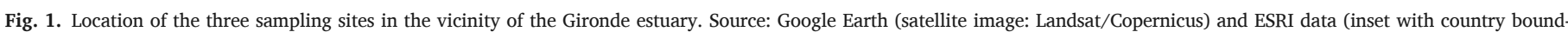
aries). Indication on the historical and pre-historical dune morpho-chronology was redrawn from Tastet and Pontee (1999); distribution not referenced. 


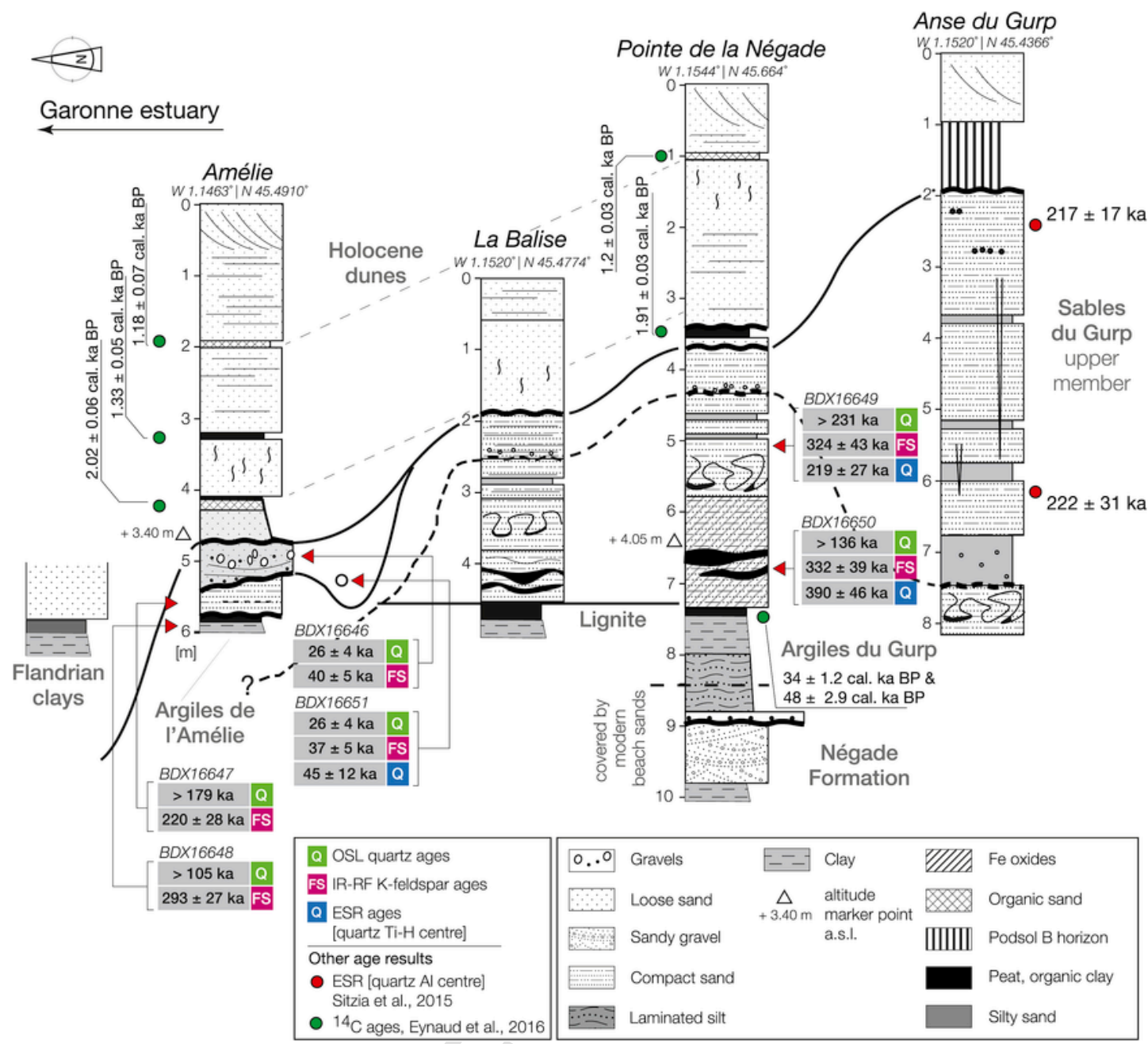

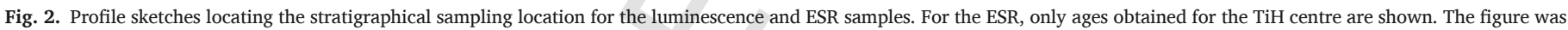
redrawn and slightly modified based on the work by Bosq et al. (in press).

\section{Study area}

The research area is located in the northern part of the Aquitaine basin, south-west France and part of the 'Les Landes de Gascogne' (e.g., Tastet and Pontee, 1998). The area forms a low-lying, triangle shaped plateau, slightly inclined westwards and covered by sandy deposits (e.g., Mercier, 2013). The coastline extends over $270 \mathrm{~km}$ along the "Golfe de Gascogne" (Bay of Biscay) from the Bidasoa estuary in the south to the Gironde estuary in the north (Bernon and Mallet, 2016). The region is dominated by a large transgressive Holocene coastal dune complex with a succession of dune generations and dune systems. Starting from the coastline, the first $0.2 \mathrm{~km}-10 \mathrm{~km}$ are dominated by coastal dunes, followed by a large continental dune/sandsheet complex which stretches more than $100 \mathrm{~km}$ inland ('Sable des Landes'; cf. Legigan, 1979; Tastet and Pontee, 1998; Sitzia et al., 2015). Based on the work by Legigan (1979) and our own studies (Bertran et al., 2009, 2011; Sitzia et al., 2015), Bertran et al. (2013) suggested that the region was a "sandsheet-dominated desert in the past", which seemed to be confirmed by Sitzia et al. (2017) based on morphometric analysis, grain-size gradients and geochemical data (major and minor elements). The known local Late Pleistocene depositional history appears to be mainly driven by climate-controlled water table fluctuations and the exposition to deflation of large parts of the continental shelf during main glacial periods (in particular MIS 4 to MIS 2).

The three study sites (North Amélie 10, South Amélie 2, Négade 1), chosen for luminescence and ESR dating are located in the northern part of the Aquitaine basin on the Médoc Peninsula (Fig. 1) and have been exposed by recent coastal erosion. The Médoc area is a plateau, slightly inclined towards the Atlantic Ocean. The Holocene coastal dunes in this area were last active from ca. 1,500 BP to $200 \mathrm{BP}$ (radiocarbon data, Tastet and Pontee, 1998; Eynaud et al., 2016) and dominate the current morphology. These Holocene sands and muddy peats are stratigraphically preceded by a succession of Pleistocene deposits including estuarine clay, freshwater peat, and aeolian sand with cryogenic features (frost wedges, cryoturbation) (Tastet, 1999; O'Brien and Jones, 2003; Bosq et al., in press). The most noticeable layer in the lower part of the standard profile revised by Tastet (1999) below the Pleistocene sands (Sables du Gurp) is black coloured and composed of compacted, locally sandy peat ('Lignite'). This layer overlays a greenish grey laminated clay layer termed 'Argiles du Gurp', which forms the base of the sequence visible along the coastal cliff. Based on already existing ${ }^{14} \mathrm{C}$ dating (Dubreuilh, 1971) of the 'Lignite' layer, and well aware of the limitations of the method, Tastet (1999) concluded that the lower part of the profile must be older than 50 ka. Later work by Sitzia et al. (2015) using ESR dating of quartz (Al centre), suggests a deposition of the upper sands (cf. Fig. 2) during MIS 8 or MIS 7, rendering an 
MIS 3 age of the 'Lignite' layer unlikely. Following the basic principles of the multiple-centres (MC) approach (Toyoda et al., 2000), these ESR ages using the $\mathrm{Al}$ centre should in a first instance be considered as maximum ages. For further details and a full stratigraphical description of the study area, we refer to Bosq et al. (in press) and Stéphan et al. (in press).

\section{Material and methods}

This section is intentionally kept short to focus on the main technical and methodological aspects of OSL, IR-RF and ESR dating. Full details on the equipment and applied methods are given in the supplement (Sec. 1 supplement).

\subsection{Sampling, sample preparation and environmental dosimetry}

Samples for luminescence and ESR dating were taken from the cleaned profile wall using opaque steel cylinders during daylight conditions (profile photos: Figs. S1-S3). The sample preparation at the IRAMAT-CRP2A followed commonly applied luminescence sample preparation procedures for the minerals quartz and K-feldspar (e.g., Preusser et al., 2008). The grain size range of $100-200 \mu \mathrm{m}$ (coarse grain) was separated by wet sieving. The coarse feldspar grains were not further treated with HF (cf. the argumentation by Duller, 1992). To determine the $\mathrm{U}$, Th, and $\mathrm{K}$ concentration, raw sediment material was taken from the sampling position for high-resolution $\gamma$-ray spectrometry analysis. The in situ $\gamma$-dose rate was measured using a portable $\gamma$-ray spectrometer (Canberra Inspector 1000, 1.5 in x 1.5 in, LaBr probe) and derived from the threshold approach (principle described in Mercier and Falguères, 2007; Guérin and Mercier, 2011).

\subsection{Luminescence dose evaluation}

Luminescence measurements were carried out using a Freiberg Instruments (1) lexsyg research reader (Richter et al., 2013) for IR-RF measurements on coarse grain K-feldspar and (2) a lexsyg SMART (Richter et al., 2015) for green-OSL measurements on coarse-grained quartz, respectively. Bleaching of the IR-RF signal was done using the inbuilt solar simulator for $3 \mathrm{~h}$ (ca. $3180 \mathrm{~kJ} 24 \mathrm{~h}$ of Bordeaux sun in June; calculated using 'palinsol'; Crucifix, 2016) applying the settings suggested by Frouin et al. (2017) (Fig. S4). Bleaching of the quartz samples (dose recovery test, preheat plateau test) was carried out on a window sill of the laboratory using 2015's early spring sun- light in Bordeaux. All luminescence measurements (OSL, IR-RF) were carried out on large multiple-grain aliquots of $5 \mathrm{~mm}$ diameter with ca. 700 grains/aliquot (number of grains estimated using the function calc_AliquotSize(), Burow, 2018).

For measuring the quartz luminescence signal in the UV wavelength range an adapted single aliquot regenerative (SAR) dose protocol (Murray and Wintle, 2000) was used (preheat: $220{ }^{\circ} \mathrm{C}$, cutheat: $160{ }^{\circ} \mathrm{C}$, read temperature: $125{ }^{\circ} \mathrm{C}$ for $80 \mathrm{~s}$ ). The protocol parameters were obtained from combined preheat plateau and preheat dose recovery tests (cf. Fig. S5; cutheat in all cases $160{ }^{\circ} \mathrm{C}$ ). IR-RF signals of K-feldspar samples were recorded at $70{ }^{\circ} \mathrm{C}$. The protocol settings followed the recommendation by Frouin et al. (2017) (cf. Table S1). For the $D_{\mathrm{E}}$ estimation the vertical sliding method suggested by Kreutzer et al. (2017a) and introduced by Murari et al. (accepted) was applied.

\subsection{ESR dose evaluation}

Three quartz samples (BDX16649, BDX16650 and BDX16651) were selected for ESR dating. These samples were processed in accordance with the MC approach (Toyoda et al., 2000) and following the standard multi-grain multiple-aliquot additive dose (MAAD) method as described in Duval et al. (2017). The purified 100-200 $\mu \mathrm{m}$ quartz grain fraction (see above) was split into 12 aliquots for each sample. Ten aliquots were irradiated using a ${ }^{137} \mathrm{Cs}$-source (Gammacell 1000; $~ 6.8 \mathrm{~Gy} \mathrm{~min}^{-1}$ ) at the Centro Nacional de Investigación sobre la Evolución Humana (CENIEH, Burgos, Spain) with the following doses: $\{100$ p.0, 394.6, 796.1, 1598.9, 3197.9, 6001.1, 10003.1, 15002.8, 2 ¿1\} Gy. The non-bleachable residual ESR signals of the $\mathrm{Al}$ centre were measured after bleaching an aliquot of each natural sample in a SOL 500 (Dr Hönle) solar light simulator for about $1,500 \mathrm{~h}$.

Low temperature ( $90 \mathrm{~K}$ ) ESR measurements were carried out at Geochronology Facilities of the CENIEH with an EMXmicro 6/1 Bruker X-band ESR spectrometer coupled to a standard rectangular ER 4102ST cavity. Details about the setup and about its stability over time can be found in Duval and Guilarte Moreno (2012). Further measurement conditions are given as supplementary information Sec. 1.3.2. For both, the $\mathrm{Al}$ and $\mathrm{Ti}$ centres, each aliquot was measured three times after $\sim 120^{\circ}$ rotation in the cavity in order to consider angular dependence of the signal due to sample heterogeneity. Then, ESR measurements were repeated three to four times over distinct days to evaluate the repeatability of the resulting $D_{\mathrm{E}}$ values. Al and Ti ESR intensities (Fig. 3) were extracted as follows: the ESR in-

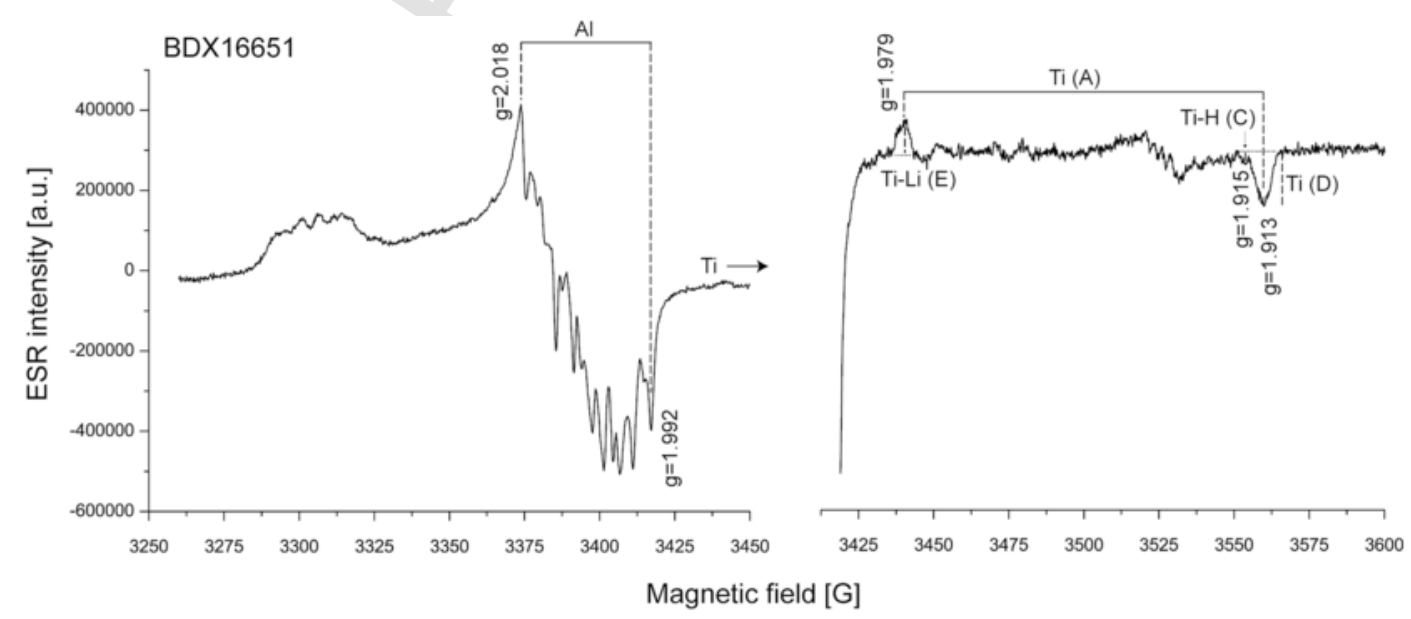

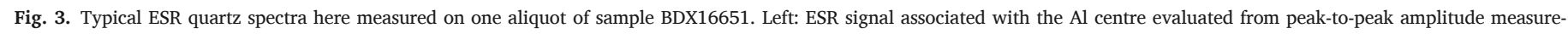

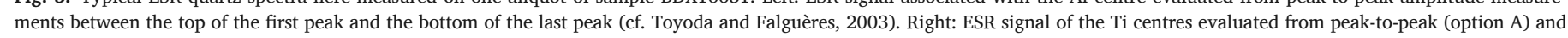
peak-to-baseline (options C, D and E) amplitude measurements following the different options described in Duval and Guilarte (2015). 
tensity of the Al signal was evaluated from peak-to-peak amplitude measurements between the top of the first peak and the bottom of the $16^{\text {th }}$ peak (Toyoda and Falguères, 2003). The ESR intensity of the different Ti centres was evaluated in four different ways (cf. Duval and Guilarte, 2015), namely option A, C (pure FiH centre), D and E (pure TiLi centre; cf. supplement). ESR intensities of $\mathrm{Al}$ and Ti centres were corrected by the corresponding receiver gain value, number of scans, aliquot mass and a temperature correction factor (Duval and Guilarte Moreno, 2012).

Dose-response curve (DRC) fitting was performed using the software Microcal OriginPro ${ }^{T M}$ (version 8.5), which uses the Levenberg-Marquardt (cf. Moré, 1978) algorithm and a minimum chi-square estimation. For the $\mathrm{Al}$ centre, an exponential + linear (EXP + LIN) function was fitted through the pooled experimental points with data weighted by the inverse of the squared ESR intensity $\left(1 / \mathrm{I}^{2}\right)$ (Duval, 2012). $D_{\mathrm{E}}$ values were obtained by back extrapolation of the EXP + LIN function after subtraction of the residual ESR intensity derived from the UV-bleaching experiment (so called 'total-bleach' method; Forman et al., 2000). For the Ti centres, the single saturating exponential function (SSE) was used and results were compared to those derived from the Ti-2 function. Fitting was performed with data that were either not weighted (equal weights $\mathrm{EW})$, or by the inverse of the squared ESR intensities $\left(1 / \mathrm{I}^{2}\right)$ or by the inverse of the squared experimental errors $\left(1 / \mathrm{s}^{2}\right.$ ) (cf. Duval et al., 2017 for details). The goodness-of-fit was assessed through the adjusted r-square $\left(r^{2}\right)$ value, accounting for the degrees of freedom of the system (see the OriginPro 8 User Guide for further details). Typical DRCs are shown in Figs. S9-S11.

\subsection{Data analysis and age calculation}

Although most of the data inputs are common for both ESR and luminescence dating, dose rate evaluation and age calculations were carried out independently, i.e. following the standard procedure that is usually applied for each method. The luminescence data analysis was done using the $\mathbf{R}$ (R Core Team, 2017) package 'Luminescence' (v0.7.4, Kreutzer et al., 2012, 2017b) including the $D_{\mathrm{E}}$ determination and production of related plots. For calculating the dose rate and the luminescence ages the online tool DRAC (v1.2) (Durcan et al., 2015) was used (cf. Tables S3 and S4 for applied settings) through the $\mathbf{R}$ package 'Luminescence'. An $a$-value of $0.07 \pm 0.01$ was estimated for the K-feldspar samples (Kreutzer et al., accepted). Ages are consistently quoted as mean and standard deviation $(1 \sigma)$.

ESR age calculations were performed using ESR-Qz (v0), a non-commercial SCILAB (http://www.scilab.org) based program, with error assessed through Monte Carlo simulations. ESR age errors are given at $1 \sigma$. Additionally, dose rate values were also calculated using the DRAC software (here: v1.1) for comparison (Durcan et al., 2015). Detailed applied settings are given in Table S5. Long-term water content was estimated from a modified approach to that proposed by Sauer et al. (2016) (cf. Sec. 1.4 supplement).

\subsection{Additional analyses}

The chemical compositions of feldspar samples BDX16650 and BDX16651 were investigated using energy dispersive X-ray spectroscopy (EDX) at the IRAMAT-CRP2A. Measurements were carried out on a JEOL JSM-6460LV, equipped with an Oxford Instruments $X$-Max (51-XMX0002) detector, operating with an accelerating voltage of $20 \mathrm{kV}$ and a beam current of $55 \mu \mathrm{A}$. Automated grain recognition (Oxford Instruments INCA version 4.11) was used to scan 140 grains of sample BDX16650 and 245 grains of sample BDX16651, respectively. For all samples, grain-size analyses were carried out in the PACEA (Université de Bordeaux) on a Horiba LA-950 laser particle size analyser (cf. Bosq et al., in press) and results are shown in Figs. S13-S14. The grain-size data were taken to estimate the water content of the sediment derived from the pore volume distribution (Sec. 1.4 supplement).

\section{Results}

\subsection{Dose rate evaluation and related analyses}

High-resolution $\gamma$-ray spectrometry results (Table S9) reveal a heterogeneous dosimetry reflecting the sediment characteristic. The concentration ranges from $0.78 \pm 0.12 \mathrm{ppm}$ to $4.64 \pm 0.29 \mathrm{ppm}$ for $U$ and from $2.27 \pm 0.04 \mathrm{ppm}$ to $15.83 \pm 0.15 \mathrm{ppm}$ for Th. The potassium concentration ranges from $0.90 \pm 0.01 \%$ to $1.94 \pm 0.03 \%$. For two samples (BDX16647 and BDX16648) we found significant disequilibria in the $\mathrm{U}$ decay chain (Fig. S12). In both cases, the equivalent U concentration obtained from ${ }^{210} \mathrm{~Pb}$ is significantly higher than the mean equivalent $\mathrm{U}$ concentration; indicating a ${ }^{210} \mathrm{~Pb}$ excess. These disequilibria are likely caused by recent influx processes, e.g., rainwater and are not relevant for the timeframe of interest in our study (e.g., Krbetschek et al., 1994) and have not been further considered. By contrast, differences in the $\mathrm{U}$ concentrations determined from the pre- ${ }^{226} \mathrm{Ra}$ (equivalent $\mathrm{U}$ concentration determined from nuclides preceding ${ }^{226} \mathrm{Ra}$ in the natural ${ }^{238} \mathrm{U}$ decay chain) and post- ${ }^{226} \mathrm{Ra}$ nuclides (equivalent $\mathrm{U}$ concentration determined from nuclides following ${ }^{226} \mathrm{Ra}$ in the natural ${ }^{238} \mathrm{U}$ decay chain; for both samples higher values for post- ${ }^{226}$ Ra nuclide) suggest post-sedimentary $\mathrm{Ra}$ enrichment due to the groundwater flow. This situation poses two dosimetric scenarios for each sample. However, the impact on the final environmental dose rate remains small at ca. 2\% (BDX16648) and 7\% (BDX16647). In addition to this uncertainty, for sample BDX16648 we found strongly developed hydromorphic features indicating a water saturation and lowering the external dose rate contribution.

Unlike for IR-RF dating, dose rate calculation for ESR dating were carried out assuming an internal dose rate of $0.050 \pm 0.030 \mathrm{~Gy} \mathrm{ka}{ }^{-1}$ and considering a small, but not negligible, external $\alpha$-dose rate representing $<2 \%$ of the total dose rate (assumed to be zero for quartz fraction measured with OSL). Comparison tests show that DRAC total dose rate values differ by $<3 \%$ for the three samples, suggesting that both programs, ESR-Qz and DRAC, provide highly consistent results.

The grain size analysis revealed that five out of six samples are composed of mainly sand and silty sand (Figs.: S13, S14). This is not surprising given the sandy nature of the sediments but it can be seen as further justification for the chosen grain size range of 100-200 $\mu \mathrm{m}$ used for ESR and luminescence measurements. Sample BDX16648 differs from the other samples and is dominated by silt and clay with a high $\mathrm{U}$ ( $\sim 4.7 \mathrm{ppm}$ vs $\sim 1.3 \mathrm{ppm}$; mean of other samples) and Th $(\sim 15.8 \mathrm{ppm}$ vs $\sim 4.1 \mathrm{ppm}$; mean of other samples) concentration. These $\mathrm{U}$ and Th concentrations yield to a high environmental dose rate, which is partly compensated by the presumably high moisture content due to the higher field capacity of clay in comparison to sand (cf. Sec. 4.1).

\subsection{OSL dating}

Green-OSL measurements were carried out on all six samples. Pre-tests, here an OSL SAR based test on three aliquots per sample to roughly estimate the dose region of the $D_{\mathrm{E}}$, revealed that only for samples BDX16646 and BDX16651 the natural signal, recorded in the UV, lies below signal saturation. Preheat plateau and preheat 
dose recovery tests were carried out only on sample BDX16646 and settings were assumed to be valid also for sample BDX16651. The results for these laboratory experiments are displayed in Fig. S5, indicating that the given dose could be best recovered with a preheat at $220{ }^{\circ} \mathrm{C}$ (measured/given dose ratio $=0.95 \pm 0.04$ ). TL preheat and OSL shine-down curves show no unexpected pattern, but good luminescence characteristics, i.e. rapid OSL decaying signal, isolated ' $110{ }^{\circ} \mathrm{C}$ ' TL peak (cf. Fig. S6). The DRCs of the two studied quartz samples have been best fitted with a SSE. To investigate the dose-response curve characteristics of the samples in signal saturation, we additionally recorded one DRC up to ca. $1.3 \mathrm{kGy}$ for sample BDX16648. We observed a considerable dose-quenching of the green stimulated UV signal above ca. 720 Gy and a natural signal $\left(L_{n} / T_{n}\right)$ clearly above the highest dose point (Fig. S8).

The $D_{\mathrm{E}}$ distributions for samples BDX16646 and BDX16651 (Fig. S7) show coefficients of variation $\left(\mathrm{c}_{\mathrm{v}}\right)$ of $13.7 \%$ (BDX16646) and $11.2 \%$ (BDX16651; only accepted aliquots) and somewhat larger than it may be expected from the stratigraphy showing no signs of disturbance or of post-depositional reworking. We assume that this scatter reflects rather the coarse sampling (probe tube diameter: $4.2 \mathrm{~cm}$ ) than bleaching components. Age results (mean \pm standard deviation) are similar for both samples: $25.5 \pm 3.9 \mathrm{ka}(\mathrm{BDX} 16646)$ and $26.1 \pm 3.5 \mathrm{ka}(\mathrm{BDX} 16651)$ indicating a deposition in outgoing MIS 3 or at the onset of MIS 2 (taken into account the $1 \sigma$-uncertainty of each sample). Due to the saturation of the UV signal, we report only minimum ages for the samples BDX16647 to BDX16650 obtained from the pre-tests placing all samples in the MIS 5 and older.

\subsection{IR-RF dating}

In comparison to OSL signals, where bleaching of the signal can be expected within seconds (Godfrey-Smith et al., 1988), much longer bleaching times are needed to reset the IR-RF signal (cf. Frouin et al., 2015). While the bleaching time in nature is unknown, the $\mathrm{RF}_{70}$ protocol (Frouin et al., 2017) assumes that the natural signal can be reset within ca. $3 \mathrm{~h}(10,000 \mathrm{~s})$ in the solar simulator given the bleaching settings proposed by Frouin et al. (2017) (cf. Fig. S4). To test whether the chosen bleaching settings were sufficient, we carried out IR-RF bleaching tests for samples BDX16646 (three aliquots) and BDX16648 (two aliquots). Each aliquot was bleached in consecutively bleaching steps of $1,000 \mathrm{~s}$ each, interrupted by IR-RF measurements at $70^{\circ} \mathrm{C}$ for $100 \mathrm{~s}$ (10 channels). The total bleaching time per aliquot was $19,000 \mathrm{~s}$, the results are shown in Fig. 4. Each point displays the count sum of ten channels. The dashed vertical

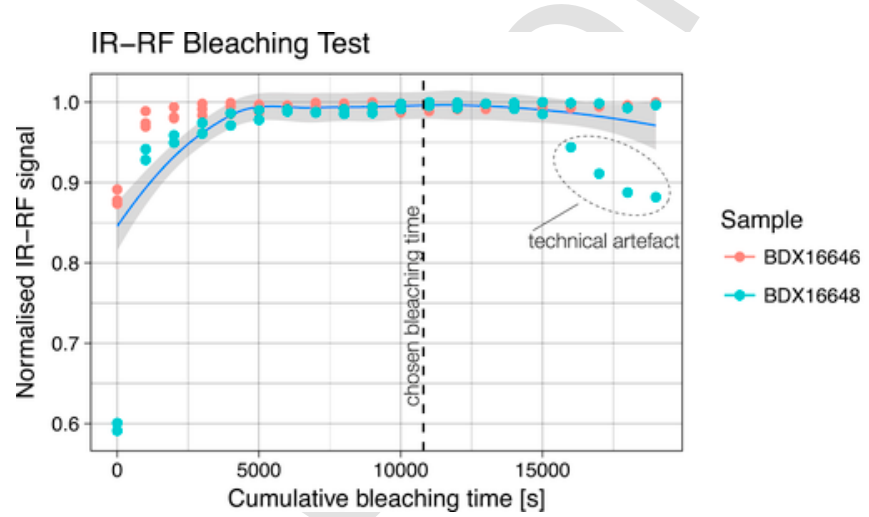

Fig. 4. Results of the IR-RF bleaching tests for the samples BDX16646 (three aliquots) and BDX16648 (two aliquots). The dashed vertical line indicates the value used in the final IR-RF measurement protocol. The bleaching was carried out in the inbuilt solar simulator of the lexsyg research reader, at $70^{\circ} \mathrm{C}$. The IR-RF signal was reset after ca. 5,000 s. The outliers for sample BDX16648 at ca. 15,000 s are caused by a technical error. line indicates the value used in the final IR-RF measurement protocol. For both samples, a bleaching plateau was already reached after $5,000 \mathrm{~s}$. The outliers (marked as 'technical artefact' in Fig. 4), were caused by a severe geometry change triggered by a hardware defect of the measurement system.

Dose recovery tests are considered as routine test for conventional SAR OSL dating (e.g., Wintle and Murray, 2006), so it appears natural to apply such test for IR-RF using the $\mathrm{RF}_{70}$ protocol. Fig. 5 displays the results for five aliquots of sample BDX16651 (give dose 2,000 s-114 Gy) and the estimates for two different types of data analysis (1) with the horizontal (black points) approach (Frouin et al., 2017) as well as the combination of horizontal and vertical sliding (red points) (Kreutzer et al., 2017a; Murari et al., accepted). This last approach was introduced to counter the geometry change induced light level change (Kreutzer et al., 2017a) observed on the reader used for our experiments. The given dose could be best recovered with the combination of both approaches (ratios: $0.95 \pm 0.04$ for horizontal sliding vs $1.02 \pm 0.02$ for horizontal + vertical sliding), but both approaches give similar results within $2 \sigma$ uncertainties. For this study, the combined horizontal and vertical sliding method was used to analyse all IR-RF signals.

Typical IR-RF curves are displayed in Fig. 6. Independent of the palaeodose of the samples (BDX16646 $112 \mathrm{~Gy}$; BDX16648 $1,073 \mathrm{~Gy}$ ), the sliding yields a good match of the natural (red points) and the regenerated signal (green crosses). No curve offset was observed, indicating good luminescence characteristics and small individual standard errors (lower than ca. 2\%).

Additional EDX analyses on samples BDX16650 and BDX16651 (Figs. S15, S16) revealed that both samples are enriched by K-feldspar with a contribution of Na-feldspar and partly quartz. The obtained internal mean potassium concentration (individual uncertainties assumed $\ll 10 \%$ ) was $12.8 \pm 3.6 \%$. This value is slightly higher than expected for 'pure' K-feldspar (Huntley and Baril, 1997) and it may be related to other mineral phases, e.g., Leucite (Gupta, 2015). For the final age calculation we applied an internal K concentration of $12 \pm 2 \%$, which covers the value reported by Huntley and Baril (1997) and accounts for the observed large dispersion of $\mathrm{K}$ concentrations in the analysed two samples (cf. supplement).

In contrast, the $D_{\mathrm{E}}$ distribution obtained for IR-RF measurements displayed an inter-aliquot scatter larger than individual standard errors (Fig. 7). Krbetschek et al. (2000) believed that the individual composition of grains plays a significant role, but also the lattice ori-

DRT IR-RF | KFS | BDX16651

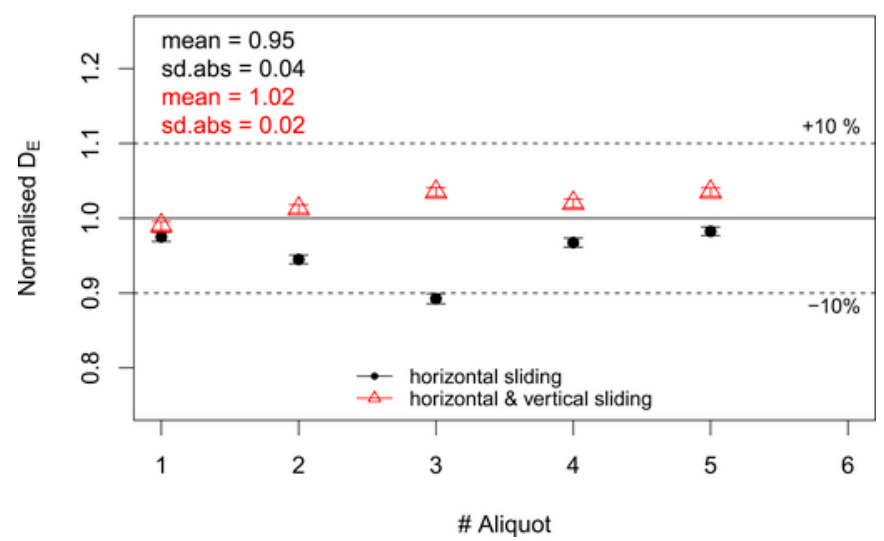

Fig. 5. Dose recovery test results of sample BDX16651 KFS with (black points) and without (red points) vertical sliding (Murari et al., accepted). The used signal integral was kept similar for both approaches. If the vertical sliding is applied, the dose can be slightly better-recovered yielding dose recovery tests results closer to unity. (For interpretation of the references to colour in this figure legend, the reader is referred to the Web version of this article.) 
A

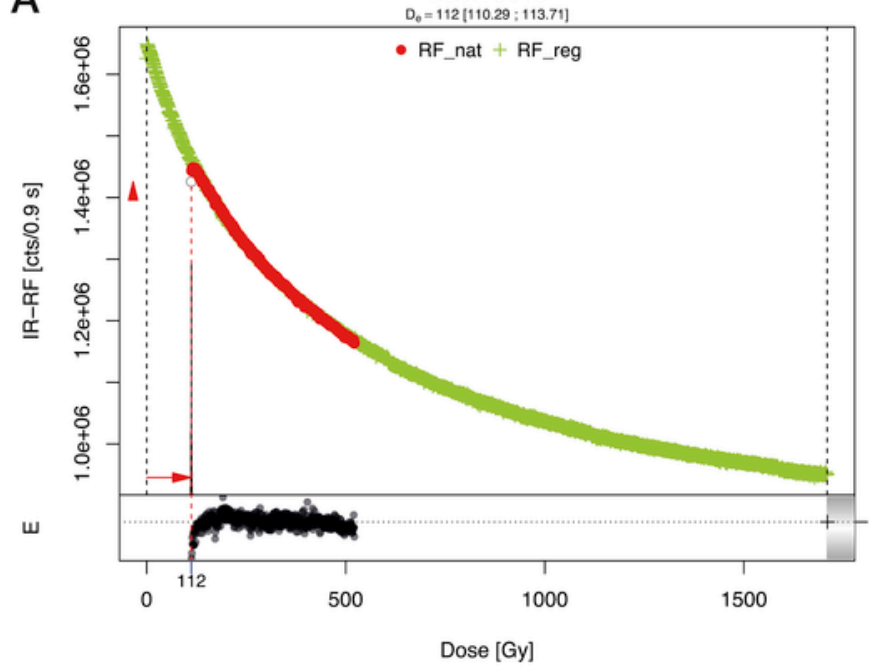

B

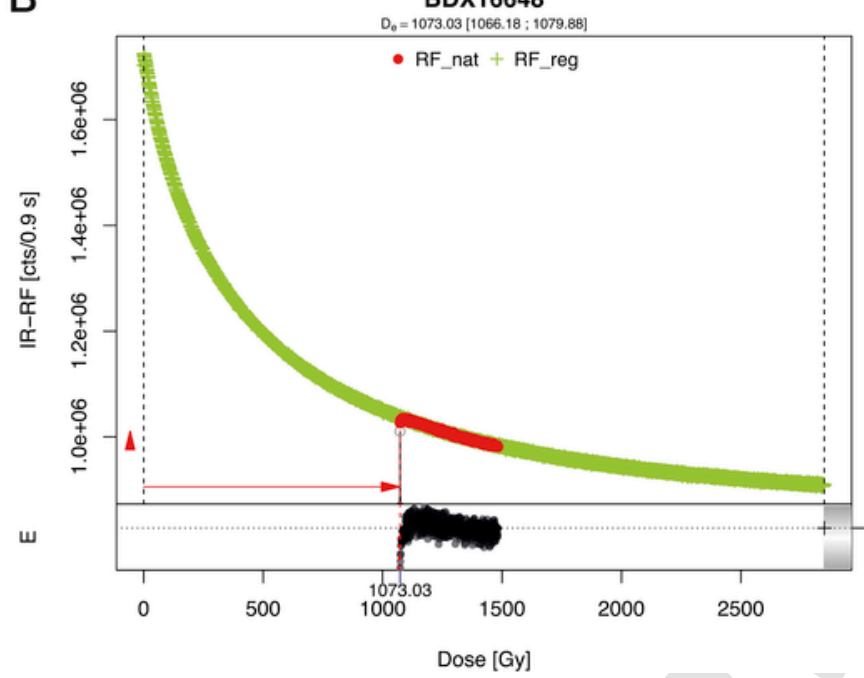

Fig. 6. Typical IR-RF curves for sample BDX16646 (A) and BDX16648 (B) after sliding. The additive natural curves (red points) match well with regenerated curves (green crosses). The initial bump seems to be positively correlated with the palaeodose (cf. Frouin et al., 2017, their supplement), but does not affect the $D_{\mathrm{E}}$ results, due to the large number of recorded channels (here 480) for the natural curves. Please note the different irradiation times for samples BDX16646 (30,000 $\mathrm{s} \cong 1,710 \mathrm{~Gy})$ and BDX16648 (49,995 s 2,850 Gy). (For interpretation of the references to colour in this figure legend, the reader is referred to the Web version of this article.)

entated light emission. Kreutzer et al. (2017a) found that disc movements add another significant aliquot scatter, which can be reduced by the vertical sliding approach. Additional partial bleaching of grains cannot be excluded however, and at the current stage, such differences remain unresolved. Therefore, the arithmetic average \pm standard deviation was used for each sample to calculate the final age. In comparison with the OSL ages (BDX16646, BDX16651) the IR-RF ages render systematically older depositional ages (BDX16646: $40.2 \pm 5.4$ ka; BDX16651: $37.0 \pm 4.9 \mathrm{ka}$ ), though similar within $2 \sigma$ errors. Results for samples BDX16647 and BDX16648 suggest depositional ages of $234.5 \pm 31.0 \mathrm{ka}(219.6 \pm 27.8 \mathrm{ka})$ and $289.6 \pm 26.1 \mathrm{ka}(293.0 \pm 26.6$ $\mathrm{ka}$ ) assuming the dosimetric scenario based on pre- ${ }^{226} \mathrm{Ra}$ equivalent $\mathrm{U}$ concentrations. The number in brackets assuming a post- ${ }^{226} \mathrm{Ra}$ equivalent U dosimetric scenario. These ages correspond to MIS 7 (BDX16647) and MIS 8 (BDX16648). For samples BDX16649 and BDX16650 IR-RF ages are: $324.6 \pm 43.0$ ka (MIS 8 to MIS 10) and $331.5 \pm 38.8$ ka (MIS 8 to MIS 11).

\subsection{Multiple-centres ESR dating}

\subsubsection{Fitting results}

Fitting results derived from the measurement of the $\mathrm{Al}$ centre are shown in Table S6 and the DRCs can be found in Fig. S9. The reliability of the measurements and of the fitting results were assessed through a series of proxies. First, the ESR intensity repeatability was found to be excellent for samples BDX16650 and BDX16651 (2.7\% and 1.9\%, respectively), while the variability observed for BDX16649 was ca. $6.6 \%$ (Table S6). This resulted in $D_{\mathrm{E}}$ variability of between $6.2 \%$ and $11.2 \%$ over the repeated measurements, which is similar to findings reported in previous studies (e.g., Duval et al., 2017; Bartz et al., 2018). All repeated $D_{\mathrm{E}}$ values were found to be within errors for a given sample. Consequently, final $D_{\mathrm{E}}$ values derived from the $\mathrm{Al}$ centre were obtained by pooling all the ESR intensities derived from the repeated measurements (cf. Duval et al., 2015b). Goodness-of-fit (adjusted $\mathrm{r}^{2}$ ) achieved for the three samples vary from 0.99 (BDX16651) to 0.97 (BDX16650) and the relative $D_{\mathrm{E}}$ errors range from $7.6 \%$ to $15 \%$. Following the criteria defined by Duval et al. (2015b), the fitting results obtained for sample BDX16651 may be considered as reliable, while those derived from the other two samples seem questionable due to the moderate $(0.988)$ to poor (0.972) goodness-of-fit. This might be explained by some scattered points in the low dose region of the DRCs of those two samples (Fig. S9).

The FiH centre (option C; Table S8; Fig. S10) shows significantly higher variability given the very weak ESR intensities measured. For the present samples, they represent on average $30 \%, 31 \%$ and $24 \%$ of the ESR intensity measured with option A for samples BDX16649, BDX16650 and BDX16651, respectively. These values are somewhat similar to those measured in studies by Duval and Guilarte (2015) for a set of six samples $(<37 \%)$ but appear to be significantly lower than those observed in the Cuesta de la Bajada samples (62-65\%, Duval et al., 2017). The measurement repeatability is ranging from $13.2 \%$ to $17.1 \%$, inducing a $D_{\mathrm{E}}$ variability over three different days of between $19.8 \%$ and $26.9 \%$ (Table S7). In light of these results, it did not appear meaningful to pool the repeated ESR intensities for the $D_{\mathrm{E}}$ evaluation. The final $D_{\mathrm{E}}$ was obtained by considering the arithmetic average ESR intensities (and associated standard deviation) derived from the three repeated measurements. The curve fitting was carried out with three different configurations: (1) SSE function until the maximum ESR intensity $\left(D_{\max }=3.2 \mathrm{kGy}\right)$ and data weighting by $1 / \mathrm{I}^{2},(2)$ Ti-2 function over the full dose range and no data weighting (EW), (3) Ti-2 function over the full dose range and data weighting by $1 / \mathrm{s}^{2}$. Figure $\mathrm{S} 10$ shows the final DRCs for the TiH centre (option C). As expected, configuration (2) provides the highest $D_{\mathrm{E}}$ values, given the leverage effect induced by the most irradiated points. This is counter-balanced by weighting the data points, and configurations (1) and (3) provide more consistent $D_{\mathrm{E}}$ values and more reduced $D_{\mathrm{E}}$ errors (Table S7). For samples BDX16649 and BDX16650, $D_{\mathrm{E}}$ values derived from configuration (3) are preferred for the age calculation because the fitting is carried out over the full dose range with an acceptable goodness-of-fit. In contrast, for BDX16651 the reliability of the $D_{\mathrm{E}}$ derived from (3) may reasonably be questioned given the expectedly large error obtained (>50\%). Consequently, the $D_{\mathrm{E}}$ derived from configuration (1) (which is, although smaller, $1 \sigma$ consistent with that obtained from (3)) is preferred for the age calculation. However, although it displays a slightly higher goodness-of-fit, the adjusted $\mathrm{r}^{2}$ value $(<0.96)$ remains considerably below the standards to ensure reliable fitting results (Duval and Guilarte, 2015).

The TiLi centre was assessed through several options, namely option A, D and E (Table S8). Usually, option D is preferred in other 

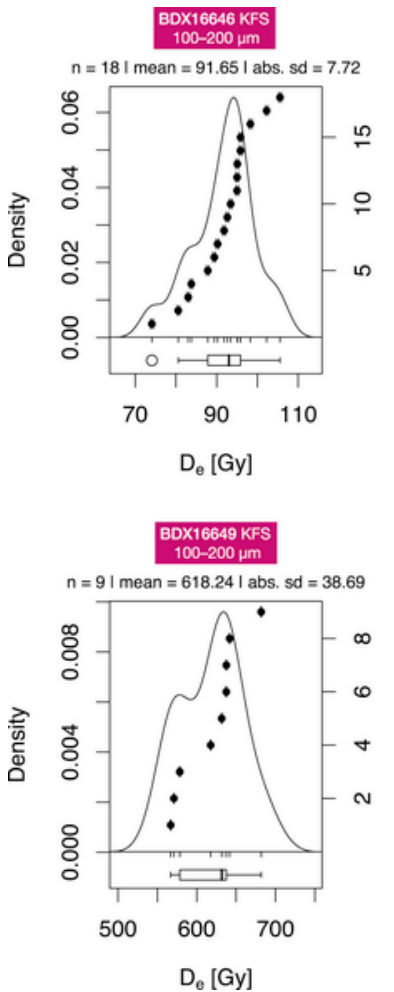
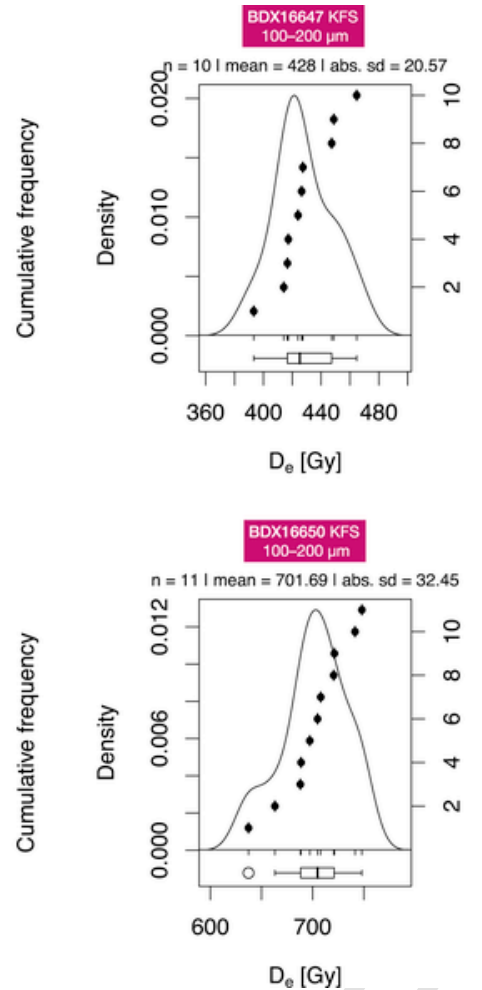
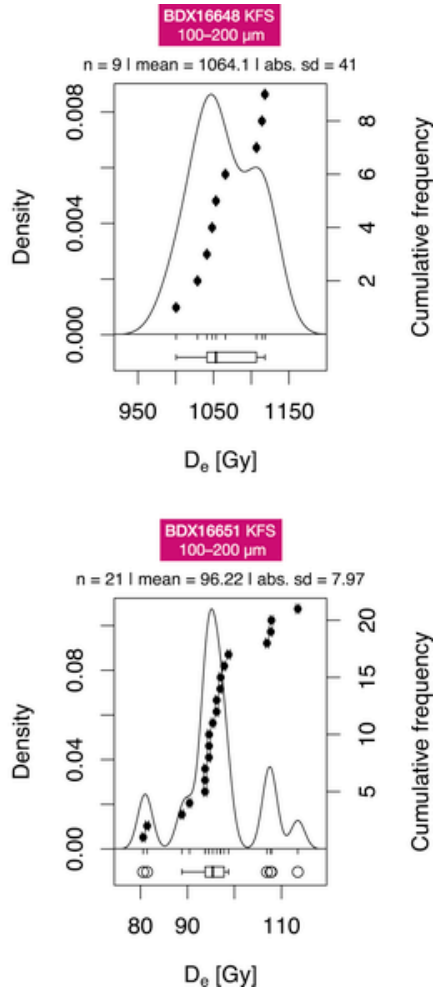

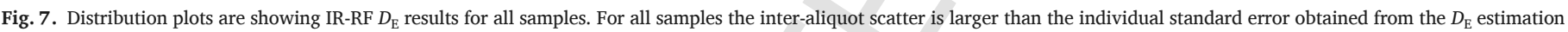
using the curve sliding method.

ESR studies of quartz (e.g., Duval et al., 2015b, 2017; Bartz et al., 2018). The final DRC for the Ti option D for sample BDX16649 is shown in Fig. S11. Measurement repeatability is ranging from $6.8 \%$ to $7.8 \%$, inducing a $D_{\mathrm{E}}$ variability of between $7.7 \%$ and $10.2 \%$ over three distinct days. For a given sample, all repeated $D_{\mathrm{E}}$ values were consistent at $1 \sigma$. Those values are in between of those obtained for the $\mathrm{Al}$ and $\mathrm{TiH}$ centres (Table S6-S8). As expected, fitting results derived from the use of the Ti-2 function with equal weights (EW) provide the highest $D_{\mathrm{E}}$ values, although $1 \sigma$-consistent with those derived from the SSE $\left(1 / \mathrm{I}^{2}\right)$ and Ti-2 $\left(1 / \mathrm{s}^{2}\right)$, which are both in close agreement (Table S8). These results demonstrate that the choice of the fitting function and data weighting option has a limited impact on the $D_{\mathrm{E}}$ value. Like for the TiH centre, the SSE was fitted until the dose point showing the maximum ESR intensity. For option $\mathrm{D}$, this corresponds to the dose point at $D_{\max }=15 \mathrm{kGy}$, while this was $D_{\max }=3.2 \mathrm{kGy}$ for option C, demonstrating thus that the $\mathrm{TiH}$ reaches a "saturation" much earlier than the TiLi centre, which is consistent with previous observations (Duval and Guilarte, 2015). For age calculation, $D_{\mathrm{E}}$ values derived from Ti-2 function $\left(1 / \mathrm{s}^{2}\right)$ are used, as in Bartz et al. (2018). The goodness-of-fit ranges between 0.982 and 0.995 (adjusted $r^{2}$ ). Altogether (repeatability, goodness-of-fit), ESR data obtained for option D may be considered as reliable from a methodological point of view. For comparison, ESR fitting results from options A and E (Ti-2 function; EW) are also provided in Table S8: they are both in close agreement with option D (Ti-2 function; EW) for samples BDX16649 and BDX16650, while option E provides a significantly higher $D_{\mathrm{E}}$ value for BDX16651, which is most likely due to a poor goodness-of-fit (adjusted $\mathrm{r}^{2}=0.969$ ).

A summary of the final fitting results considered for the ESR age calculation of each centre (Al, TiH and TiLi) is given in Fig. 8. Two samples (BDX16649 and BDX16651) follow the same typical $D_{\mathrm{E}}$ pattern, with the highest $D_{\mathrm{E}}$ values obtained with the $\mathrm{Al}$ centre and the lowest values derived from the $\mathrm{TiH}$. In contrast, for BDX16650 the highest $D_{\mathrm{E}}$ value is achieved with the TiLi centre, while the Al-centre is lower but nevertheless within $1 \sigma$ error. This inversion simply caused by the relatively poor goodness-of-fit achieved with the Al centre (low adjusted $\mathrm{r}^{2}$ value), as mentioned above.

In accordance with the basic principles of the MC approach, the comparison of the results derived from each centre suggests that the signals of the $\mathrm{Al}$ and $\mathrm{Ti}-\mathrm{Li}$ (D) centres have been incompletely reset during sediment transport for BDX16649 and BDX16651. For these samples, these centres will only provide maximum possible dose estimates, while the $\mathrm{Ti}-\mathrm{H}$ signal most likely yields the closest estimate of the true burial dose.

\subsubsection{ESR age results}

Samples BDX16649 and BDX16650 were collected from the same section, the first one being approximately located $2 \mathrm{~m}$ above the second (Fig. 2). The Al centre provides ESR age estimates of $781 \pm 82$ ka and $449 \pm 71 \mathrm{ka}$, respectively for these two samples, which are not stratigraphically consistent. As explained above, this is most likely due to questionable fitting results obtained for BDX16650. These two samples show very close $\mathrm{Ti}-\mathrm{Li}$ (option $\mathrm{D}$ ) age results for the two samples (546 $\pm 69 \mathrm{ka}$ and $558 \pm 67 \mathrm{ka}$ ), while the $\mathrm{Ti}-\mathrm{H}$ shows much younger estimates of $219 \pm 27 \mathrm{ka}$ and $390 \pm 46 \mathrm{ka}$ for BDX16649 and BDX16650, respectively. Based on the principles of the MC approach, and given the significantly faster bleaching rate of the $\mathrm{Ti}-$ $\mathrm{H}$ compared to that of the $\mathrm{Ti}-\mathrm{Li}$ centre, the $\mathrm{Ti}-\mathrm{H}$ results should be considered as the closest ESR estimates of the true burial age of these samples. For sample BDX16649, OSL dating of quartz yields a minimum age of $231 \mathrm{ka}$, while the corresponding IR-RF result is of $325 \pm 43 \mathrm{ka}$. Consequently, the $\mathrm{Ti}-\mathrm{H}$ result of $219 \pm 27 \mathrm{ka}$ appears to be somewhat underestimated in comparison with the semi-independent age control provided by the luminescence method. The reason for this apparent discrepancy is unknown, although another possible interpretation of the results would simply be to consider the Ti $-\mathrm{H}$ and IR-RF ages as consistent within $2 \sigma$. In any case, this possi- 


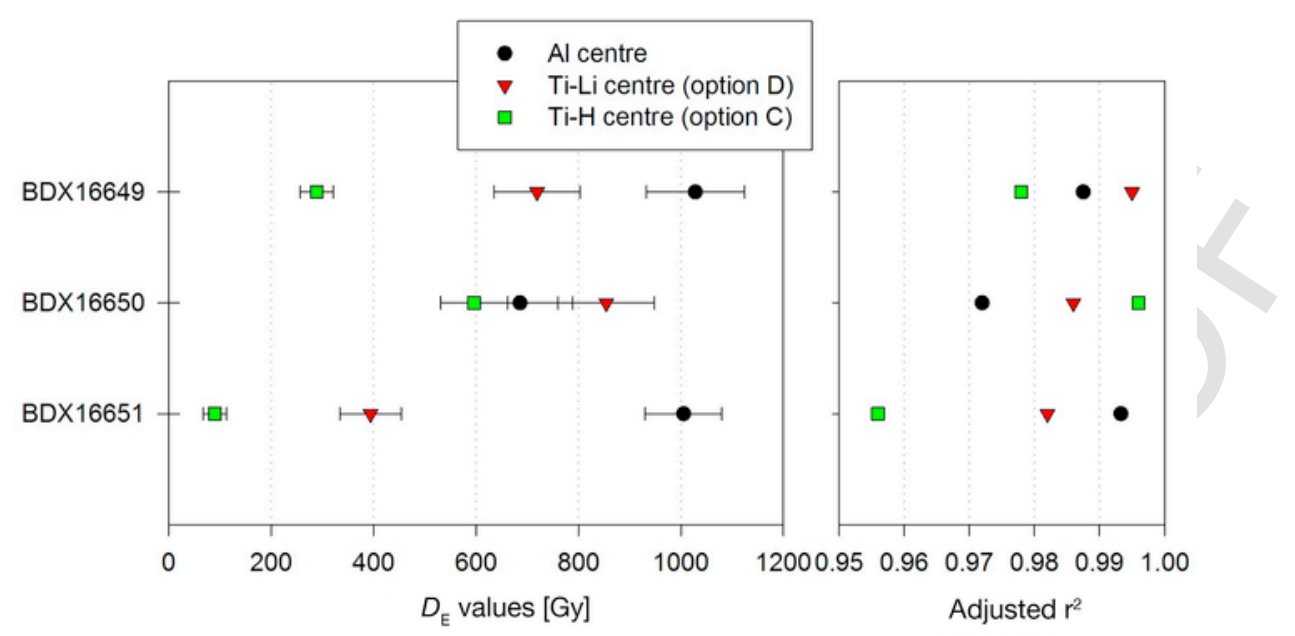

Fig. 8. Comparison of ESR age results for different centres and options.

ble underestimation is not the result of a systematic bias between methods, as the other two samples show a different pattern. For example, sample BDX16650 yields a $\mathrm{Ti}-\mathrm{H}$ result of $390 \pm 46 \mathrm{ka}$, which is in good agreement with the corresponding IR-RF age of $332 \pm 39 \mathrm{ka}$, and compatible with the OSL age of $>136 \mathrm{ka}$.

Sample BDX16651 was collected from much younger deposits. The expected Late Pleistocene chronology is most likely very close or even beyond the current limits of the ESR method applied to quartz. The low radiation sensitivity of the Al centre renders it difficult to register small dose values of several tens of Gy. To our knowledge, the number of dating attempts performed on Late Pleistocene samples is very limited (e.g., Voinchet et al., 2013). As a result, the Al centre provides a $D_{\mathrm{E}}$ value that is much higher than that of the Ti centres (Table 1), most likely overestimating the true burial dose. This may be either due to the low radiation sensitivity mentioned above or more likely, to an incomplete reset of the signal during sediment transport. The resulting ESR age should be interpreted as a maximum possible estimate for this sample. The same comment may apply to the TiLi age, as its potential to accurately register small dose values $(<100 \mathrm{~Gy})$ needs further research. In contrast, the $\mathrm{TiH}$ centre provides the youngest age estimates ( $45 \pm 12 \mathrm{ka}$ ). Although the precision is lower given the questionable reliability of the fitting results (Fig. S10), the age is in agreement with the IR-RF age for BDX16651 of $37 \pm 5$ ka.

In summary, the three samples measured by ESR show TiH ESR age estimates that are $2 \sigma$ consistent with the IR-RF results. In contrast, the TiLi and $\mathrm{Al}$ centres provide age estimates that are systematically overestimated, of at least $68 \%$ and $36 \%$ older than those derived from the IR-RF method. The systematic ESR age overestimation given by the $\mathrm{Al}$ centre is most likely due to its relatively slow bleaching rate in conjunction with the sedimentary environment and transport conditions which do not ensure a complete resetting of the signal (Voinchet et al., 2015). A similar hypothesis may be proposed for the TiLi centre: although it displays a much faster bleaching rate than the AI centre, the rate remains nevertheless significantly slower than that of the $\mathrm{TiH}$ centre (Duval et al., 2017). Consequently, the age differences between the $\mathrm{TiLi}$ and $\mathrm{TiH}$ signals may be interpreted as being likely the results of an incomplete reset of the ESR signal of the latter during sediment transport. However, another possible reason cannot be neglected. Interestingly, the present work is actually

Table 1

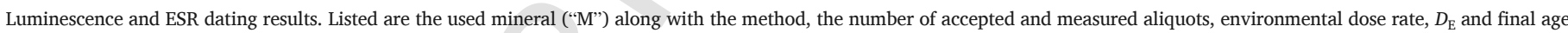
results. For details, we refer to Tables S10 (luminescence dating) and S11 (ESR dating).

\begin{tabular}{|c|c|c|c|c|c|c|}
\hline Sample & M & Method & $\mathrm{N}$ & $\dot{D}_{\text {Env. }}\left[\mathrm{Gy} \mathrm{ka}^{-1}\right]$ & $D_{\mathrm{E}}[\mathrm{Gy}]$ & Age [ka] \\
\hline \multirow[t]{2}{*}{ BDX16646 } & $\mathrm{Q}$ & OSL & $22 / 24$ & $1.7 \pm 0.1$ & $42.0 \pm 5.7$ & $25.5 \pm 3.9$ \\
\hline & FS & IR-RF & $18 / 18$ & $2.3 \pm 0.2$ & $91.7 \pm 7.2$ & $40.2 \pm 5.4$ \\
\hline \multirow[t]{3}{*}{ BDX16647 } & $\mathrm{Q}$ & OSL & 3 & $1.3 \pm 0.1$ & $>238$ & $>179$ \\
\hline & FS & IR-RF & $10 / 20$ & $2.0 \pm 0.2$ & $428.0 \pm 20.6$ & $219.6 \pm 27.8$ \\
\hline & FS & IR-RF(a) & & $1.8 \pm 0.2$ & $428.0 \pm 20.6$ & $234.5 \pm 31.0$ \\
\hline \multirow[t]{3}{*}{ BDX16648 } & $\mathrm{Q}$ & OSL & 3 & $2.8 \pm 0.1$ & $>300$ & $>105$ \\
\hline & FS & IR-RF & $9 / 10$ & $3.6 \pm 0.2$ & $1064.1 \pm 41$ & $293.0 \pm 26.6$ \\
\hline & FS & IR-RF(a) & & $3.7 \pm 0.2$ & $1064.1 \pm 41$ & $289.6 \pm 26.1$ \\
\hline \multirow[t]{5}{*}{ BDX16649 } & $\mathrm{Q}$ & OSL & 3 & $1.3 \pm 0.1$ & $>300$ & $>231$ \\
\hline & FS & IR-RF & $9 / 14$ & $1.9 \pm 0.2$ & $618.2 \pm 38.7$ & $324.6 \pm 43.0$ \\
\hline & $\mathrm{Q}$ & ESR (Al) & & $1.3 \pm 0.1$ & $1028 \pm 96$ & $781 \pm 82$ \\
\hline & $Q$ & $\operatorname{ESR}(\mathrm{Ti}-\mathrm{H})$ & & & $289 \pm 32$ & $219 \pm 27$ \\
\hline & $\mathrm{Q}$ & ESR $(\mathrm{Ti}-\mathrm{Li})$ & & & $719 \pm 84$ & $546 \pm 69$ \\
\hline \multirow[t]{5}{*}{ BDX16650 } & $\mathrm{Q}$ & OSL & 3 & $1.5 \pm 0.1$ & $>206$ & $>136$ \\
\hline & FS & IR-RF & $11 / 16$ & $2.1 \pm 0.2$ & $701.7 \pm 32.5$ & $331.5 \pm 38.8$ \\
\hline & $\mathrm{Q}$ & ESR (Al) & & $1.5 \pm 0.1$ & $686 \pm 103$ & $449 \pm 71$ \\
\hline & $\mathrm{Q}$ & $\mathrm{ESR}(\mathrm{Ti}-\mathrm{H})$ & & & $596 \pm 65$ & $390 \pm 46$ \\
\hline & $\mathrm{Q}$ & $\operatorname{ESR}(\mathrm{Ti}-\mathrm{Li})$ & & & $854 \pm 94$ & $558 \pm 67$ \\
\hline \multirow[t]{5}{*}{ BDX16651 } & $\mathrm{Q}$ & OSL & $17 / 19$ & $1.9 \pm 0.1$ & $50.7 \pm 5.7$ & $26.1 \pm 3.5$ \\
\hline & FS & IR-RF & $21 / 21$ & $2.6 \pm 0.2$ & $96.2 \pm 8.0$ & $37.0 \pm 4.9$ \\
\hline & $\mathrm{Q}$ & ESR (Al) & & $2.0 \pm 0.2$ & $1005 \pm 76$ & $506 \pm 65$ \\
\hline & $\mathrm{Q}$ & $\operatorname{ESR}(\mathrm{Ti}-\mathrm{H})$ & & & $90 \pm 23$ & $45 \pm 12$ \\
\hline & $\mathrm{Q}$ & $\mathrm{ESR}(\mathrm{Ti}-\mathrm{Li})$ & & & $394 \pm 60$ & $198 \pm 37$ \\
\hline
\end{tabular}


one of the very few studies in which meaningful ESR results could be derived from the $\mathrm{TiH}$ signal. This is due to the weak ESR intensity of the signal that is usually measured in quartz samples (e.g., Duval and Guilarte, 2015), although there may be some exceptions like Cuesta de la Bajada site (Duval et al., 2017). Our current knowledge and understanding of how the $\mathrm{TiH}_{\mathrm{A}}$ and TiLi centres behave and might be connected are very limited. In their comparison study, using both OSL and ESR methods, Beerten and Stesmans (2006) observed strong dose overestimates from the TiLi centre with samples showing a significant concentration of $\mathrm{TiH}$ centre, while grains with very weak $\mathrm{TiH}$ centre show good TiLi results. A similar conclusion may be derived from the dating study performed at the Acheulean site of Porto Maior, Spain (Méndez-Quintas et al., 2018), whose temporal framework is close to that of the Pointe de la Négade section. There, the TiLi and luminescence dating results are in excellent agreement for all but one sample. This sample from the uppermost part of the sequence was actually the only one displaying a measurable $\mathrm{TiH}$ signal, while the other ones did not show acceptable $\mathrm{TiH}$ intensities to ensure meaningful dose estimates. Similarly, the relatively high $\mathrm{TiH}$ signal observed in the samples from the present study may explain the apparently overestimated TiLi ages in comparison with the TiH, IR-RF and OSL results. This is consistent with the previous observations by Beerten and Stesmans (2006), although further work will be required to better characterize the composition of the quartz samples.

Finally, the possible presence of a residual, unbleachable, component of the $\mathrm{Ti}-\mathrm{Li}$ signal as being one of the reasons to explain the age overestimation can reasonably be discarded here. In the present study, the UV-bleached aliquot did not show any measurable Ti signal. This is consistent with previous UV bleaching experiments showing that this ESR signal can be fully reset after several tens of hours (e.g., Duval et al., 2017) and contradicts the observations by Beerten et al. (2006). This suggests that the presence of an unbleachable component of the $\mathrm{Ti}-\mathrm{Li}$ ESR signal may be sample dependent.

\section{Discussion}

Our goal was to test IR-RF on K-feldspar as dating method in conjunction with OSL and multiple-centres ESR dating of quartz separates to establish a chronological framework for Quaternary deposits of the Médoc region (France).

For four out of six samples, the green stimulated OSL signal measured in UV was found to be in signal saturation, and thus these age results can only be considered as minimum estimates (Table 1). Despite, for the two more recent samples (BDX16646, BDX16651) OSL dating provided a clear chronological marker ( $\sim 22-30 \mathrm{ka})$, suggesting that the IR-RF and ESR ages (all centres) are systematically overestimated in this temporal range. We hypothesise that this overestimation likely results from an insufficient signal resetting during (short distance) transport of the sandy material from the source area in close vicinity of the sediment trap. Although OSL, IR-RF and ESR (TiH) ages are similar within $2 \sigma$ errors, the relatively slower bleaching rates of the ESR and IR-RF (Duval et al., 2017; Frouin et al., 2017) signals may be seen as a methodological limit of the IR-RF and ESR dating likely yielding overestimated, maximum ages in particular environments and temporal periods (e.g., Late Pleistocence). Another possible explanation takes into account the MAAD approach chosen for the ESR dating. The irradiation dose steps selected are likely to be not suitable for evaluating $D_{\mathrm{E}}$ values $<100 \mathrm{~Gy}$ : the first -irradiation dose was $100 \mathrm{~Gy}$, i.e. very close or even slightly higher than the $D_{\mathrm{E}}$ value. This setting may have added a non-negligible uncertainty on the dose evaluation. Future work focused on evaluating the potential of the ESR to detect small $D_{\mathrm{E}}$ values would require more irradiation points in the low dose region $(<100-200$ Gy; depending on the environmental setting).

In post-IR IRSL dating studies, a habit has been developed to subtract an experimentally obtained 'unbleachable residual' dose, which was reported to reach up to ca. $20 \mathrm{~Gy}$ in Chinese loess samples (Buylaert et al., 2011). The difficulty arising from such experiments is that the bleaching setting chosen to estimate residuals does not necessarily reflect the first signal bleaching. Frouin et al. (2017) did not find unbleachable residuals using the $\mathrm{RF}_{70}$ protocol, and to our knowledge, no such unbleachable residual subtraction is reported in the IR-RF dating literature. Besides, Krbetschek et al. (2000) reported dose determination experiments using (presumed) 'zero-age' sediments. However, their results are inconclusive and show palaeodose values up to ca. $44 \mathrm{~Gy}$ for a flood-loam in Germany, 1.3 Gy for aeolian sand from Australia, but also negative values for fluvial sands. Consequently, no suggestion was made to subtract residual doses. By contrast, Wagner et al. (2010) also recognised the possible problem of incomplete bleaching of the IR-RF signal due to the sediment transport process in conjunction with the slow bleachability of the IR-RF signal. To overcome this problem, they proposed an age determination based on an age histogram and its mode value (cf. Wagner et al., 2010). Such procedure, however, appears not to be justified in our case given the large inter-aliquot scatter which is still not well understood. Instead, we proposed an IR-RF bleaching test (Fig. 4) acting as an easy to apply protocol test ensuring that the chosen laboratory bleaching setting reaches a bleaching plateau. For future studies, it might be meaningful to collect additional surface samples, to test the general bleachability of the sediment.

In the case of samples BDX16646 (OSL age of $25.5 \pm 3.9 \mathrm{ka}$ ) and BDX16651 (OSL age of $26.1 \pm 3.5 \mathrm{ka}$ ) (cf. Fig. 2; Table 1), we consider these OSL ages as reliable estimates of the depositional ages. For all other samples, except for sample BDX16650, IR-RF and ESR may be considered as maxima ages. For sample BDX16650 the obtained ESR Ti$\mathrm{H}$ age overlaps within errors with the IR-RF age (332 $\pm 39 \mathrm{ka})$, suggesting complete signal resetting during transport. For samples BDX16647 (IR-RF: $220 \pm 28 \mathrm{ka}$ ) and BDX16648 (IR-RF: $293 \pm 27 \mathrm{ka}$ ) no ESR age was determined, so the validity of the ages can be just roughly assessed. Both ages are, however, based on narrow $D_{\mathrm{E}}$ distributions (Fig. 7) and are in stratigraphical order, even though both samples showed multiple radioactive disequilibria, and the sediment indicated hydromorphic features (strong for BDX16648).

Finally, the $D_{\mathrm{E}}$ estimate of $1,064 \pm 41$ Gy for sample BDX16648 may be seen as lying in a dose range considered in the past as the saturation level for IR-RF. Unfortunately, so far only inconclusive numbers have been reported, for instance, Trautmann et al. (1999): $500 \mathrm{~Gy}$; Krbetschek et al. (2000): 600-800 Gy; Erfurt and Krbetschek (2003): 1,300 Gy; Frouin et al. (2017): ca. 2,100 Gy. In a laboratory experiment Murari et al. (accepted) reported a successful dose recovery even up to $3,600 \mathrm{~Gy}$. However, it remains unclear to which extent this value can be transferred to natural signals and further tests on samples whose natural signals have already reached field saturation are needed. We thus consider the age of sample BDX16648 as a minimum age, although the stratigraphical interpretation by Bosq et al. (in press) indicates good credibility of this age estimate.

In this study, we applied the combined horizontal and vertical sliding to all IR-RF samples. Murari et al. (accepted) could considerably improve their dose recovery results by using this approach, and the recalculation of the results published in Frouin et al. (2017) by Kreutzer et al. (2017a) suggest that this analytical method can lead to significantly reduced inter-aliquot scatter. All samples for our study were measured on the same reader as used by Kreutzer et al. (2017a) which justifies the application of this method to tackle the encountered IR-RF light-level change. Nevertheless, conclusions be- 
yond are difficult to be drawn. Fig. 6 shows improved dose recovery tests results, whereas Fig. S17 shows that this goes along with a higher scatter, dependent on the integration limits of the natural curve (see Fig. 9).

In summary, the newly established long-term chronological framework leads to a new understanding of the palaeolandscape in the Médoc area. The dominating, abundant Holocene dunes ( $\sim 2$ ka to $\sim 1.2 \mathrm{ka}$; Fig. 2) covering thin layers of MIS 2 sands, followed by deposits of pre-Eemian age, presumably periglacial sandsheets. Based on ${ }^{14} \mathrm{C}$ dating by Dubreuilh (1971), Tastet (1999) placed the Lignite (cf. Fig. 2) at least into the MIS 4. Recent investigations by Eynaud et al. (2016) (Fig. 2) and Faye et al. (in press) using also ${ }^{14} \mathrm{C}$ dating, support this interpretation. The results by O'Brien and Jones (2003) already suggested an MIS 11 age (Holsteinian Interglacial) based on palynological inter-comparisons with European sequences. Our findings seem to confirm the initial interpretation by O'Brien and Jones (2003), supporting the theory of a progressive replacement of a tide-influenced marsh by a peaty fresh-water pond during that period and proposed that the ${ }^{14} \mathrm{C}$ ages of the basal Lignite layer should be discarded. The OSL signals of sample BDX16649 and BDX16650 show a clear saturation of the UV signal, which alone implies a chronology older than suggested by the ${ }^{14} \mathrm{C}$ dating results. Furthermore, good agreement of IR-RF and ESR ages for BDX16650 suggest a robust chronology for this sample and allow a consistent interpretation. Less obvious is the interpretation of the ages of samples BDX16647 and BDX16648. The IR-RF of BDX16647 makes the sample layer in the profile Amélie (Fig. 2) a member for the Sables du Gurp, which have been placed in MIS 8 or MIS 7 by an independent ESR dating study (Sitzia et al., 2015) on another outcrop. Unfortunately, the ESR ages by Sitzia et al. (2015) are based on the Al centre only, leaving the possibility open that the ages are overestimated. Sample BDX16648 (293 $\pm 27 \mathrm{ka}$, MIS 8/MIS 9) from the basal clay of the Amélie profile displays an age younger than the stratigraphy from the profile Pointe de la Négade would suggest for the Argiles du Gurp (MIS 11). This situation allows two interpretations: (1) Assuming that the IR-RF ages are accurate, the layer cannot belong to the Argiles du Gurp Formation but reveals a more complex stratigraphy than initially considered or (2) the IR-RF ages are largely underestimated, either

\section{Summary Luminescence \& ESR Ages}

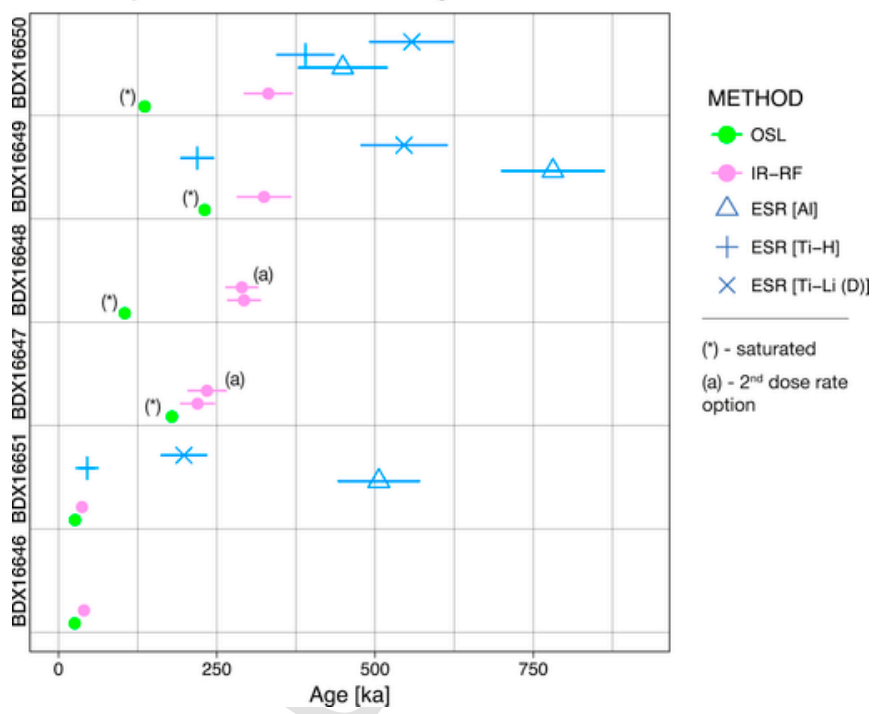

Fig. 9. Combined luminescence and ESR ages estimates as obtained during this study for all samples. The samples are ordered vertically (rows) by ascending age. Numerical results are displayed in Table 1. Minimum age results do not have associated errors, while the error bar is too small to be fully visible for the youngest samples. For details see main text. due to the encountered dosimetric problems or due to the reached saturation limit of the method itself. Although the second interpretation cannot be entirely excluded, currently the first version appears to be more likely. Therefore, the clay at Amélie is assumed to reflect MIS 9 estuarine deposits incised into the Argiles du Gurp sensu stricto. Both units were previously mistakenly attributed to a single geological formation because of similar depositional contexts and lithofacies. For a more detailed stratigraphical discussion, we refer to Bosq et al. (in press).

\section{Conclusions}

Our study was conducted to test the progression and applicability of new chronological tools, namely IR-RF and multiple-centres ESR dating, on cover sands in the Médoc region in south-west France. It was the first time that conventional OSL dating techniques on quartz were combined with multiple-centres ESR dating on quartz and IR-RF dating on K-feldspar and therefore establish a chronological framework reaching out to the Middle Pleistocene. The studied six samples could be linked to existing chronostratigraphies based on independent dating methods (Eynaud et al., 2016; Stéphan et al., in press; Sitzia et al., 2015; O'Brien and Jones, 2003; Tastet, 1999) giving new insights into the landscape evolution in the Médoc region. However, the new age data render the chronology more complex than previously considered. We summarise our results as follows:

- Four out of six OSL quartz samples are in signal saturation, the two remaining samples give an MIS 3 age (both ages indistinguishable within error margins).

- IR-RF K-feldspar and ESR quartz ages (all centres) appear overall systematically older than the corresponding finite OSL ages (with sample BDX16651 similar within 2б). For the OSL samples not in signal saturation, this overestimation might be caused by insufficient bleaching of the IR-RF and ESR signals, although for the latter other factors may have a non-negligible role in this bias (i.e., the use of inappropriate irradiation dose steps to derive relatively small dose estimates; unusual characteristics of the quartz samples with relatively high $\mathrm{TiH}$ signal).

- Two out of three ESR ages ( TiH centre) are in good agreement with the IR-RF ages. The exact reason for which the age of BDX16649 drops out, yielding an age younger than the IR-RF signal, is still unclear. However, $\mathrm{TiH}_{\mathbf{\Lambda}}$ and IR-RF results are $2 \sigma$ consistent for this sample.

- BDX16648 may be in or close to IR-RF signal saturation and thus underestimate the true burial age.

Even though we highlighted the time-efficient measurement protocol in the introduction, it should be mentioned that the measurement time sums up to ca. 100 days for IR-RF alone given the high dose range in combination with the low dose rate of the irradiation source. IR-RF has been proven to be a valuable dating tool to extend the temporal range of chronological studies to the Middle Pleistocene time range. Furthermore, this new comparison study shows the interest of the ESR multiple-centres approach, and in particular the importance of measuring $\mathrm{Ti}$ centres in addition to the $\mathrm{Al}$ centre, as previously emphasized by Duval et al. (2017). In particular, when measurable, the TiH signal appears to be quite useful for dating Middle to Late Pleistocene samples, although further work is required to better constrain its real potential and limitations. Challenging for both ESR and IR-RF methods is the slower bleaching rate compared to that of quartz OSL, which cannot be overcome for the moment and may be seen as the major limitation of our study. However, despite this potential issue, it is worth stressing that previous ESR dating applications have nevertheless indirectly demonstrated that complete 
bleaching may be achieved in nature, and even for the slow-bleaching Al signal, by providing highly consistent results with independent age control (e.g., Duval et al., 2015a; Bartz et al., 2018; Méndez-Quintas et al., 2018; Ingicco et al., 2018; Pereira et al., 2018). The sedimentary context and transport conditions have indeed a significant influence on the bleaching efficiency achieved by a given signal (see Voinchet et al., 2015). In the future, modern analogue samples should be taken along with the sediments of interest to obtain more data on the bleachability of the IR-RF and ESR signals. Furthermore, unanswered also remained the reason for inter-aliquot scatter observed for the IR-RF ages. However, we assume that this challenge can be addressed in the future with spatially resolved IR-RF measurements currently underway at the IRAMAT-CRP2A aimed at analysing individual K-feldspar grains.

\section{Acknowledgements}

We are thankful to Nathan Brown and Frank Preusser for constructive and helpful comments on our manuscript. The authors are also thankful to Mélanie Saint-George and Virginie Moineau for carrying out the sample preparation in the luminescence lab in Bordeaux. Yannick Lefrais is thanked for conducting the EDX measurements. Part of the work for this study was carried out in the framework of the project Inter-LabEx LaScArBx/COTE (2013-2015) coordinated by FV (LaScArBx) and FE (COTE), supported by the ANR (ANR-10-IDEX-03-02). The ESR dating study has been funded by the Australian Research Council Future Fellowship grant FT150100215. SK received financial support from the LaScArBx. LaScArBx is a research programme supported by the ANR (ANR-10-LABX-52).

\section{Appendix A. Supplementary data}

Supplementary data to this article can be found online at https:// doi.org/10.1016/j.quageo.2018.09.005.

\section{References}

Bartz, M., Rixhon, G., Duval, M., King, G.E., Álvarez Posada, C., Parés, J.M., Brückner, H., 2018. Successful combination of electron spin resonance, luminescence and palaeomagnetic dating methods allows reconstruction of the Pleistocene evolution of the lower Moulouya river (NE Morocco). Quat. Sci. Rev. 185, 153-171.

Beerten, K., Stesmans, A., 2006. The use of Ti centers for estimating burial doses of single quartz grains: a case study from an aeolian deposit $\sim 2$ Ma old. Radiat. Meas. 41, 418-424.

Beerten, K., Lomax, J., Clémer, K., Stesmans, A., Radtke, U., 2006. On the use of Ti centres for estimating burial ages of Pleistocene sedimentary quartz: multiple-grain data from Australia. Quat. Geochronol. 1, 151-158.

Bernon, N., Mallet, C., 2016. Caractérisation de l'aléa recul du trait de côte sur le littoral de la côte aquitaine aux horizons 2025 et 2050. BRGM http://infoterre.brgm.fr/ rapports/RP-66277-FR.pdf.

Bertran, P., Allenet, G., Gé, T., Naughton, F., Poirier, P., Goñi, M.F.S., 2009. Coversand and Pleistocene palaeosols in the Landes region, southwestern France. J. Quat. Sci. 24, 259-269.

Bertran, P., Bateman, M.D., Hernandez, M., Mercier, N., Millet, D., Sitzia, L., Tastet, J.-P., 2011. Inland aeolian deposits of south-west France: facies, stratigraphy and chronology. J. Quat. Sci. 26, 374-388.

Bertran, P., Sitzia, L., Banks, W.E., Bateman, M.D., Demars, P.-Y., Hernandez, M., Lenoir, M., Mercier, N., Prodeo, F., 2013. The Landes de Gascogne (southwest France): periglacial desert and cultural frontier during the Palaeolithic. J. Archaeol. Sci. 40, 2274-2285.

Bosq, M., Bertran, P., Beauval, C., Kreutzer, S., Duval, M., Bartz, M., Mercier, N., Sitzia, L., LITAQ project members, 2018. Stratigraphy and chronology of pleistocene coastal deposits in northern Aquitaine, France: A Reinvestigation. Quaternairein press.

Burow, C., 2018. calc AliquotSize: estimate the amount of grains on an aliquot. Function version 0.31. In: Kreutzer, S., Burow, C., Dietze, M., Fuchs, M.C., Schmidt, C., Fischer, M., Friedrich, J. (Eds.), Luminescence: Comprehensive Luminescence Dating Data Analysis. R package version 0.8.4. https://CRAN.R-project.org/ package $=$ Luminescence.

Buylaert, J.P., Jain, M., Murray, A.S., Thomsen, K.J., Lapp, T., 2012. IR-RF dating of sand-sized K-feldspar extracts: a test of accuracy. Radiat. Meas. 47, 759-765.

Buylaert, J.P., Thiel, C., Murray, A.S., Vandenberghe, D.A.G., Yi, S., Lu, H., 2011. IRSL and post-IR IRSL residual doses recorded in modern dust samples from the Chinese Loess Plateau. Geochronometria 38, 432-440.
Clarke, M.L., Rendell, H.M., Pye, K., Tastet, J.P., Pontee, N.J., Masse, L., 1999. Evidence for the timing of dune development on the Aquitaine Coast, southwest France. Zeitschrift für Geomorphologie Suppl.-Bd. 116, 147-163.

Crucifix, M., 2016. palinsol: insolation for Palaeoclimate Studies. R package version 0.93 . In: https://CRAN.R-project.org/package $=$ palinsol.

Dubreuilh, J., 1971. Etude géologique des formations quaternaires du Bas-Médoc. Essai de corrélations stratigraphiques. D.E.S. Géologie, Faculté des Sciences, Université, Bordeaux I, 147 pp.

Duller, G.A.T., 1992. Luminescence Chronology of Raised Marine Terraces, South-west North Island, New Zealand. PhD thesis University of Wales, Aberystwyth, 236.

Durcan, J.A., King, G., Duller, Geoff A.T., 2015. DRAC: dose rate and age calculator for trapped charge dating. Quat. Geochronol. 28, 54-61.

Duval, M., 2012. Dose response curve of the ESR signal of the Aluminum center in quartz grains extracted from sediment. Ancient TL 30, 1-9.

Duval, M., Arnold, L.J., Guilarte, V., Demuro, M., Santonja, M., Pérez-Gonzalez, A., 2017. Electron spin resonance dating of optically bleached quartz grains from the Middle Palaeolithic site of Cuesta de la Bajada (Spain) using the multiple centres approach. Quat. Geochronol. 37, 82-96.

Duval, M., Guilarte Moreno, V., 2012. Assessing the influence of the cavity temperature on the ESR signal of Aluminum center in quartz grains extracted from sediment. Ancient TL 30, 11-16.

Duval, M., Guilarte, V., 2015. ESR dosimetry of optically bleached quartz grains extracted from Plio-Quaternary sediment: evaluating some key aspects of the ESR signals associated to the Ti-centers. Radiat. Meas. 78, 28-41.

Duval, M., Bahain, J.-J., Falguères, C., Garcia, J., Guilarte, V., Grün, R., Martínez, K., Moreno, D., Shao, Q., Voinchet, P., 2015a. Revisiting the ESR chronology of the early pleistocene hominin occupation at Vallparadís (Barcelona, Spain). Quat. Int. 389, 213-223.

Duval, M., Sancho, C., Calle, M., Guilarte, V., Peña-Monné, J.L., 2015b. On the interest of using the multiple center approach in ESR dating of optically bleached quartz grains: some examples from the Early Pleistocene terraces of the Alcanadre River (Ebro basin, Spain). Quat. Geochronol. 29, 58-69.

Erfurt, G., Krbetschek, M.R., 2003. IRSAR - a single-aliquot regenerative-dose dating protocol applied to the infrared radiofluorescence (IR-RF) of coarse-grain K-feldspar. Ancient TL 21, 35-42.

Eynaud, F., Londeix, L., Bosq, M., Faye, S., 2016. Le contexte stratigraphique général. In: Verdin, F., et al. (Eds.), Lède du Gurp (Grayan-et-l'Hôpital, Gironde) - Rapport final d'operation, Fouille programmée et sauvetages 2014-2016, (unpublished).

Faye, S., Eynaud, F., Bosq, M., Lambert, C., Verdin, F., Vequaud, P., Lodyga, O., Dériennic, H., Lebleu, P., Bujan, S., Billy, I., Matrin, B., Roussot-Larroque, J., LITAQ project members, 2018. Holocene paleoenvironmental evolution of the Medoc peninsula (SW France): insights from the sedimentological study of the archeological site of the "Lède du Gurp". Quaternairein press.

Forman, S.L., Pierson, J., Lepper, L., 2000. Luminescence geochronology. In: Sowers, J., Noller, J., WR, L. (Eds.), Quaternary Geochronology: Methods and Applications. American Geophysical Union, Washington, DC, pp. 157-176.

Frouin, M., Huot, S., Kreutzer, S., Lahaye, C., Lamothe, M., Philippe, A., Mercier, N., 2017. An improved radiofluorescence single-aliquot regenerative dose protocol for K-feldspars. Quat. Geochronol. 38, 13-24.

Frouin, M., Huot, S., Mercier, N., Lahaye, C., Lamothe, M., 2015. The issue of laboratory bleaching in the infrared-radiofluorescence dating method. Radiat. Meas. 81, 212-217.

Godfrey-Smith, D.I., Huntley, D.J., Chen, W.H., 1988. Optical dating studies of quartz and feldspar sediment extracts. Quat. Sci. Rev. 7, 373-380.

Guérin, G., Mercier, N., 2011. Determining gamma dose rates by field gamma spectroscopy in sedimentary media: results of Monte Carlo simulations. Radiat. Meas. 46, 190-195.

Gupta, A.K., 2015. Origin of Potassium-rich Silica-deficient Igneous Rocks. Springer India, New Delhi, 548.

Huntley, D.J., Godfrey-Smith, D.I., Thewalt, M.L.W., 1985. Optical dating of sediments. Nature 313, 105-107.

Huot, S., Frouin, M., Lamothe, M., 2015. Evidence of shallow TL peak contributions in infrared radiofluorescence. Radiat. Meas. 81, 237-241.

Hütt, G., Jaek, I., Tchonka, J., 1988. Optical dating: K-Feldspars optical response stimulation spectra. Quat. Sci. Rev. 7, 381-385.

Ingicco, T., van den Bergh, G.D., Jago-on, C., Bahain, J.-J., Chacón, M.G., Amano, N., Forestier, H., King, C., Manalo, K., Nomade, S., Pereira, A., Reyes, M.C., Sémah, A.-M., Shao, Q., Voinchet, P., Falguères, C., Albers, P.C.H., Lising, M., Lyras, G., Yurnaldi, D., Rochette, P., Bautista, A., de Vos, J., 2018. Earliest known hominin activity in the Philippines by 709 thousand years ago. Nature 557, 233-237.

Krbetschek, M.R., Rieser, U., Zöller, L., Heinicke, J., 1994. Radioactive disequilibria in palaeodosimetric dating of sediments. Radiat. Meas. 23, 485-489.

Krbetschek, M.R., Trautmann, T., Dietrich, A., Stolz, W., 2000. Radioluminescence dating of sediments: methodological aspects. Radiat. Meas. 32, 493-498.

Kreutzer, S., Dietze, M., Burow, C., Fuchs, M.C., Schmidt, C., Fischer, M., Friedrich, J., 2017b. Luminescence: comprehensive luminescence dating data analysis. R package version 0.7.4. In: https://cran.r-project.org/package = Luminescence.

Kreutzer, S., Lauer, T., Meszner, S., Krbetschek, M.R., Faust, D., Fuchs, M., 2014. Chronology of the Quaternary profile Zeuchfeld in Saxony-Anhalt/Germany - a preliminary luminescence dating study. Z. Geomorphol. 58, 5-26.

Kreutzer, S., Martin, L., Dubernet, S., Mercier, N., 2018. The IR-RF alpha-efficiency of K-feldspar. Radiat. Meas. https://doi.org/10.1016/j.radmeas.2018.04.019, accepted.

Kreutzer, S., Murari, M.K., Frouin, M., Fuchs, M., Mercier, N., 2017a. Always remain suspicious: a case study on tracking down a technical artefact while measuring IR-RF. Ancient TL 35, 20-30. 
Kreutzer, S., Schmidt, C., Fuchs, M.C., Dietze, M., Fischer, M., Fuchs, M., 2012. Introducing an R package for luminescence dating analysis. Ancient TL 30, 1-8.

Lauer, T., Krbetschek, M.R., Frechen, M., Tsukamoto, S., Hoselmann, C., Weidenfeller, M., 2011. Infrared radiofluorescence (IR-RF) dating of middle pleistocene fluvial archives of the Heidelberg Basin (Southwest Germany). Geochronometria 38, 23-33.

Legigan, P., 1979. L'élaboration de la formation du Sables des Landes. Depôt residuel de l'énvironnement sédimentaire pliocene pleistocene centre Aquitain, vol. 9, Memories de l'Institut de Geologie du Bassian d'Aquitaine, Talence, 451.

Li, B., Li, S.-H., 2011. Luminescence dating of K-feldspar from sediments: a protocol without anomalous fading correction. Quat. Geochronol. 6, 468-479.

Lisiecki, L.E., Raymo, M.E., 2005. A Pliocene-Pleistocene stack of 57 globally distributed benthic $\delta^{18} \mathrm{O}$ records. Paleoceanography 20,1-17.

Méndez-Quintas, E., Santonja, M., Pérez-González, A., Duval, M., Demuro, M., Arnold, L.J., 2018. First evidence of an extensive Acheulean large cutting tool accumulation in Europe from Porto Maior (Galicia, Spain). Sci. Rep. 8, 3082.

Mercier, D., 2013. Géomorphologie de la France. Dunod. 320.

Mercier, N., Falguères, C., 2007. Field gamma dose-rate measurement with a NaI(Tl) detector: re-evaluation of the 'threshold' technique. Ancient TL 25, 1-4.

Moré, J.J., 1978. The Levenberg-Marquardt algorithm: implementation and theory. In: Numerical Analysis, Lecture Notes in Mathematics. Springer, Berlin, Heidelberg, Berlin, Heidelberg, pp. 105-116.

Murari, M.K., Kreutzer, S., Fuchs, M., 2018. Further investigations on IR-RF: dose recovery and correction. Radiat. Meas. https://doi.org/10.1016/j.radmeas.2018.04.017, accepted.

Murray, A.S., Wintle, A.G., 2000. Luminescence dating of quartz using an improved single-aliquot regenerative-dose protocol. Radiat. Meas. 32, 57-73.

Novothny, , Frechen, M., Horváth, E., Krbetschek, M.R., Tsukamoto, S., 2010. Infrared stimulated luminescence and radiofluorescence dating of aeolian sediments from Hungary. Quat. Geochronol. 5, 114-119.

O'Brien, C.E., Jones, R.L., 2003. Early and Middle Pleistocene vegetation history of the Médoc region, southwest France. J. Quat. Sci. 18, 557-579.

Pereira, A., Nomade, S., Moncel, M.-H., Voinchet, P., Bahain, J.-J., Biddittu, I., Falguères, C., Giaccio, B., Manzi, G., Parenti, F., Scardia, G., Scao, V., Sottili, G., Vietti, A., 2018. Integrated geochronology of Acheulian sites from the southern Latium (central Italy): insights on human-environment interaction and the technological innovations during the MIS 11-MIS 10 period. Quat. Sci. Rev. 187, 112-129.

Preusser, F., Degering, D., Fuchs, M., Hilgers, A., Kadereit, A., Klasen, N., Krbetschek, M.R., Richter, D., Spencer, J.Q.G., 2008. Luminescence dating: basics, methods and applications. Eiszeitalt. Ggw.(Quat. Sci. J.) 57, 95-149.

R Core Team, 2017. R: a Language and Environment for Statistical Computing. R Foundation for Statistical Computing, Vienna, Austria https://r-project.org.

Richter, D., Richter, A., Dornich, K., 2013. Lexsyg - a new system for luminescence research. Geochronometria 40, 220-228.

Richter, D., Richter, A., Dornich, K., 2015. Lexsyg smart - a luminescence detection system for dosimetry, material research and dating application. Geochronometria 42, 202-209.

Sauer, D., Kadereit, A., Kühn, P., Kösel, M., Miller, C.E., Shinonaga, T., Kreutzer, S., Herrmann, L., Fleck, W., Starkovich, B.M., Stahr, K., 2016. The loess-palaeosol sequence of Datthausen, SW Germany: characteristics, chronology, and implications for the use of the Lohne Soil as a marker soil. Catena 146, 10-29.

Schaarschmidt, M., Fu, X., Li, B., Marwick, Ben, Khaing, K., Douka, K., Roberts, R.G., 2018. pIRIR and IR-RF dating of archaeological deposits at Badahlin and Gu Myaung Caves - first luminescence ages for Myanmar. Quat. Geochronol. 1-9. https://doi.org/10. 1016/j.quageo.2018.01.001.
Sitzia, L., Bertran, P., Bahain, J.-J., Bateman, M.D., Hernandez, M., Garon, H., de Lafontaine, G., Mercier, N., Leroyer, C., Queffelec, A., Voinchet, P., 2015. The Quaternary coversands of southwest France. Quat. Sci. Rev. 124, 84-105.

Sitzia, L., Bertran, P., Sima, A., Cherry, P., Queffelec, A., Rousseau, D.D., 2017. Dynamics and sources of last glacial aeolian deposition in southwest France derived from dune patterns, grain-size gradients and geochemistry, and reconstruction of efficient wind directions. Quat. Sci. Rev. 170, 250-268.

Stéphan, P., Arnaud-Fassetta, G., Bosq, M., Bertrand, F., Colin, A., Stéphane, C., Coutelier, C., Eynaud, F., Serge, S., Verdin, F., 2018. Holocene coastal changes along the North Médoc Peninsula: new insights from Amélie beach deposits. Quaternairein press.

Spooner, N.A., 1992. Optical dating: preliminary results on the anomalous fading of luminescence from feldspars. Quat. Sci. Rev. 11, 139-145.

Tastet, J.-P., 1999. Le Pléistocène de la façade atlantique du Nord-Médoc (France) : État des connaissances sur la lithologie et la chronostratigraphie des " Argiles du Gurp » s.l. Quaternaire 10, 199-212.

Tastet, J.-P., Pontee, N.I., 1998. Morpho-chronology of coastal dunes in Médoc. A new interpretation of Holocene dunes in Southwestern France. Geomorphology 25, 93-109.

Thomsen, K.J., Murray, A.S., Jain, M., Bøtter-Jensen, L., 2008. Laboratory fading rates of various luminescence signals from feldspar-rich sediment extracts. Radiat. Meas. 43, 1474-1486.

Toyoda, S., Falguères, C., 2003. The method to represent the ESR signal intensity of the aluminium hole center in quartz for the purpose of dating. Adv. ESR Appl. 20, 7-10.

Toyoda, S., Voinchet, P., Falguères, C., Dolo, J.M., Laurent, M., 2000. Bleaching of ESR signals by the sunlight: a laboratory experiment for establishing the ESR dating of sediments. Appl. Radiat. Isot. 52, 1357-1362.

Trautmann, T., Krbetschek, M.R., Dietrich, A., Stolz, W., 1998. Investigations of feldspar radioluminescence: potential for a new dating technique. Radiat. Meas. 29, 421-425.

Trautmann, T., Krbetschek, M.R., Dietrich, A., Stolz, W., 1999. Feldspar radioluminescence: a new dating method and its physical background. J. Lumin. 85, 45-58.

Trautmann, T., Krbetschek, M.R., Dietrich, A., Stolz, W., 2000. The basic principle of radioluminescence dating and a localized transition model. Radiat. Meas. 32, 487-492.

Voinchet, P., Toyoda, S., Falguères, C., Hernandez, M., Tissoux, H., Moreno, D., Bahain, J.J., 2015. Evaluation of ESR residual dose in quartz modern samples, an investigation on environmental dependence. Quat. Geochronol. 30 (Part B), 506-512.

Voinchet, P., Yin, G., Falguères, C., Liu, C., Han, F., Sun, X., Bahain, J.J., 2013. ESR dose response of $\mathrm{Al}$ center measured in quartz samples from the Yellow River (China): implications for the dating of Upper Pleistocene sediment. Geochronometria 40, 341-347.

Wagner, G.A., Krbetschek, M.R., Degering, D., Bahain, J.J., Shao, Q., Falguères, C., Voinchet, P., Dolo, J.M., Garcia, T., Rightmire, G.P., 2010. Radiometric dating of the type-site for Homo heidelbergensis at Mauer, Germany. Proc. Natl. Acad. Sci. 107, 19726-19730.

Wintle, A.G., 1973. Anomalous fading of thermoluminescence in mineral samples. Nature 245, 143-144.

Wintle, A.G., 2008. Fifty years of luminescence dating. Archaeometry 50, 276-312.

Wintle, A.G., Murray, A.S., 2006. A review of quartz optically stimulated luminescence characteristics and their relevance in single-aliquot regeneration dating protocols. Radiat. Meas. 41, 369-391. 